Christoph Strosetzki (Hg.) Prop. in Muinste.

\title{
Geschichte der spanischen Literatur
}




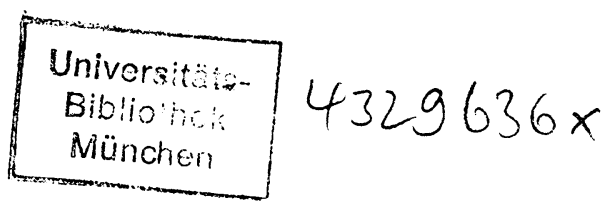

CIP-Titelaufnahme der Deutschen Bibliothek

Geschichte der spanischen Literatur / Christoph Strosetzki (Hg.). - Tübingen : Niemeyer, 1991 NE: Strosetzki, Christoph [Hrsg.]

ISBN 3-484-50307-6

(C) Max Niemeyer Verlag GmbH \& Co. KG, Tübingen 1991

Das Werk einschließlich aller seiner Teile ist urheberrechtlich geschützt. Jede Verwertung außerhalb der engen Grenzen des Urheberrechtsgesetzes ist ohne Zustimmung des Verlages unzulässig und strafbar. Das gilt insbesondere für Vervielfältigungen, Übersetzungen, Mikroverfilmungen und die Einspeicherung und Verarbeitung in elektronischen Systemen. Printed in Germany.

Druck: Gulde-Druck GmbH, Tübingen

Buchbinder: Heinr. Koch, Tübingen 
Inhalt

Albert Gier (Bamberg)

12. - 14. Jahrhundert: Lyrik, Epik, Roman und Drama

1. Geschichtlicher Überblick

2. Christen, Juden und Araber 2

3. Die Jarchas

4. Die epische Dichtung

5. Die galegoportugiesische Lyrik

6. Der 'mester de clerecía'

7. Literatur am Hof von Alfonso el Sabio

8. Die Anfänge des Romans

9. Anfänge der kastilischen Lyrik

Bibliographie

Dietrich Briesemeister (Berlin)

Mittelalterliche Fachprosa

Bibliographie

Karl Kohut (Eichstätt)

Das 15. Jahrhundert

0. Methodische Vorbemerkungen $\quad 35$

1. Geschichtlicher Überblick 35

2. Die Entwicklung des literarischen Bewußtseins $\quad 40$

3. Versdichtung 49

$\begin{array}{ll}3.1 \text { Lyrik } & 49\end{array}$

3.2 Die gelehrte Epik $\quad 53$

3.3 Satirische und didaktische Dichtung $\quad 54$

3.4 Die wichtigsten Autoren $\quad 56$

3.5 Die volkstümliche Epik: der Romancero $\quad 64$

4. Prosa 66

$\begin{array}{ll}4.1 \text { Geschichtsschreibung } & 67\end{array}$

4.2 Satire, Didaktik und Moralistik $\quad 70$

4.3 Der Roman 71

5. Das Theater $\quad 74$

$\begin{array}{ll}\text { Bibliographie } & 77\end{array}$ 
Christoph Strosetzki (Düsseldorf)

Der Roman im Siglo de Oro

1. Geschichtlicher Überblick $\quad 84$

2. Einleitung $\quad 88$

3. Der Ritterroman $\quad 89$

4. Miguel de Cervantes' 'Don Quijote' 91

5. Vom sentimentalen Liebesroman zum Schäferroman 98

6. Moriskenromane und "historische" Romane 102

7. Von Heliodor ausgehende Romane und Graciáns 'Criticón' 104

$\begin{array}{ll}\text { 8. Der Schelmenroman } & 107\end{array}$

9. Die Novelle 112

Bibliographie $\quad 116$

Georges Güntert (Zürich)

Siglo de Oro: Lyrik - erster Teil: Das 16. Jahrhundert 119

1. Höfische und volkstümliche Lyrik der Cancioneros 121

2. Der Petrarkismus $\quad 122$

2.1. Boscán 124

2.2. Garcilaso 126

3. Fray Luis de León 133

4. Die Romanceros 135

5. Religiöse und mystische Lyrik: San Juan de la Cruz 137

6. Neoplatonischer Petrarkismus: Aldana 141

7. Herrera 142

Zweiter Teil: Das 17. Jahrhundert (1600-1640)

1. Literatenstreite 145

2. Lope de Vega 147

3. Góngora 149

4. Quevedo 153

Bibliographie 156

Michael Rössner (Wien)

Das Theater der Siglos de Oro

0. Einleitender Überblick 161

1. Ursprünge des spanischen Theaters: Höfisches Fest und RenaissanceEkloge in der Schule Juan del Encinas 
2. Die Tradition der Humanistenkomödie

3. Die weitere Entwicklung vom höfischen Spiel zum Theater:

Bartolomé de Torres Naharro und Gil Vicente

4. Der Beginn des kommerziellen "Volkstheaters" mit Lope de Rueda

5. Die Generation der Tragödienautoren (ca. 1575-1585):

Miguel de Cervantes Saavedra, u.a.

6. Die Vielfalt der dramatischen Gattungen im 'Siglo de Oro' 176

7. Zur Theorie des spanischen Theaters

8. Produktions- und Aufführungsbedingungen des Theaters 179

9. Die Generation Lope de Vegas

10. Die Generation Calderóns

Dietrich Briesemeister (Berlin)

Religiöse Literatur

Bibliographie

Christoph Strosetzki (Düsseldorf)

Grammatiker, Humanisten und Moralisten

Bibliographie

Manfred Tietz (Bochum)

Das 18. Jahrhundert

1. Die Wiederentdeckung und Neubewertung eines Jahrhunderts: die Aufklärung in Spanien 226

2. Die spanische Aufklärung aus zeitgenössischer Sicht 228

3. Historischer Überblick und Periodisierung des 18. Jahrhunderts. 229

4. Grundprobleme des spanischen 18. Jahrhunderts 233

4.1. Die Ausbildung eines unabhängigen "Sozialsystems Literatur" 233

4.2. Aufklärung und Religion $\quad 234$

4.3. Aufklärung und Zensur $\quad 235$

4.4. Die Reichweite der spanischen Aufklärung 236

Prosa und Essayistik

1. Der Neubeginn im Denken und in der Literatur Spaniens zu Anfang des 18. Jahrhunderts. Das Werk des P. Feijoo.

2. Die Wiederentdeckung der spanischen Vergangenheit 
3. Das Aufkommen eines Pressewesens in Spanien 243

4. Gebrauchsprosa im Dienst der Aufklärung 246

5. Cadalso, das Spanienproblem und die Folgen 247

Der Roman 250

1. Die Epigonen der Romanproduktion des Siglo de Oro 251

2. Neue Ansätze zu einem spanischen Roman 254

Die Lyrik

1. Der Vorwurf des 'afrancesamientos' und des Neoklassizismus 256

2. Zur Periodisierung 258

3. In der Kontinuität des Barock 258

4. Die Lyrik des Rokoko 259

5. Die 'philosophische' Lyrik 260

6. Der Übergang zur Romantik 264

7. Neoklassizistische Dichtung 265

8. Volkstümliche Lyrik 265

Das Theater

1. Der Streit um die spanische 'comedia antigua' und die französierte 'comedia nueva' 266

2. Zur Kontinuität des Barocktheaters 267

3. Der Kampf um ein neues Theater: Die Poetik Luzáns 269

4. Das neue Theater als Ausdruck und Medium einer neuen Ideologie 271

5. Neue Form und alte Inhalte: Huertas 'Raquel' 274

6. Formen des teatro menor: sainete und tonadilla 275

7. Das Theater von Leandro F. de Moratín 275

$\begin{array}{ll}\text { Bibliographie } & 278\end{array}$

Hans-Joachim Lope (Marburg)

Die Literatur des 19. Jahrhunderts

1. Das 19. Jahrhundert: Strukturen und Konturen

1.1 Geschichtlicher Überblick 281

1.2 Neue Medien, neue Techniken, neue Leser 284

2. Utopien, geträumt und gelebt: Die Romantik in Spanien

2.1 Spanische Romantik, europäische Romantik 285

2.2 Romantik: Wörter, Begriffe, Polemiken 286

2.3 Übergänge: Martínez de la Rosa und der Duque de Rivas 288 
2.4 Espronceda und die Lyrik der Romantik 290

2.5 Historische Romane im Zeitalter der Romantik 292

2.6 Der Sieg der Romantik auf dem Theater 294

2.7 Weichenstellungen: Gustavo Adolfo Bécquer 295

3. 'Sentido común' und realistischer Anspruch. Ideenliteratur

3.1 Der 'costumbrismo' 297

3.2 'Figaro' zwischen Literatur und Journalismus 298

3.3 'Literatura testimonial', Gebrauchsliteratur und Neuromantik 299

3.4 Standpunkte: Ideenliteratur im 19. Jahrhundert 302

4. Erzählte Wirklichkeit in der 2. Hälfte des 19. Jahrhunderts

4.1 Wege zum Realismus: Fernán Caballero 305

4.2 Pedro Antonio de Alarcón 306

4.3 Peredas Entdeckung der Nordprovinzen 307

4.4 Roman und Humanismus bei Juan Valera 308

4.5 Spanische Varianten des Naturalismus $\quad 309$

4.6 Das Universum des Benito Pérez Galdós 312

5. Übergänge: Strömungen und Gegenströmungen vor 1900

5.1 Paradigmenwechsel $\quad 315$

5.2 Angel Ganivet als Wegbereiter $\quad 316$

$\begin{array}{ll}5.3 \text { Der junge Unamuno } & 319\end{array}$

5.4 Das Trauma von $1898 \quad 320$

$\begin{array}{ll}\text { Bibliographie } & 321\end{array}$

Manfred Lentzen (Münster)

Der Roman im 20. Jahrhundert

1. Geschichtlicher Überblick $\quad 322$

2. Der Roman im 20. Jahrhundert 323

3. Die Generation von $1898 \quad 323$

4. Der "erotische" Roman 327

5. Der "novecentismo" 328

6. Der Sozialroman $\quad 330$

7. Der Roman zur Zeit des Bürgerkriegs und die späteren

Romane über den Bürgerkrieg 331

8. Der "tremendismo" 333

9. "Realismo social" und "realismo dialéctico" 334

10. Der "experimentelle" Roman 338

11. Rückkehr zu "traditionellen" Formen $\quad 341$

$\begin{array}{ll}\text { Bibliographie } & 342\end{array}$ 
Klaus Dirscherl (Passau)

Die Lyrik im 20. Jahrhundert

1. Modernismus und 98er Generation 343

2. Avantgarden der 20er und 30er Jahre 347

3. Von der Reinheit zur Revolution 352

4. 'Poesía social', kritischer Surrealismus und neuer Ästhetizismus 356

5. Lyrik als Weg der Erkenntnis 360

6. 'Novísimos' und noch jüngere: postmoderne Provokation und neuer Klassizismus in den 70er und 80er Jahren 363

Bibliographie

Wilfried Floeck (Mainz)

Das Drama im 20. Jahrhundert 368

1. Das spanische Theater um die Jahrhundertwende 369

2. Das Theater Jacinto Benavente 371

3. Die avantgardistischen Theaterexperimente des frühen 20. Jahrhunderts

4. Ramón María del Valle-Inclán: von der Mythisierung der Vergangenheit zur Entmythisierung der Gegenwart 375

5. Federico García Lorca und das Theater seiner Zeit 377

6. Das Exiltheater nach dem Bürgerkrieg 381

7. Buero Vallejo und Sastre und die "Generación Realista" 383

8. Das "Neue Spanische Theater" 388

9. Ausblick auf das spanische Theater nach Franco 389

$\begin{array}{ll}\text { Bibliographie } & 392\end{array}$

Index 393 


\section{Das Theater der Siglos de Oro}

\section{Einleitender Überblick}

Das spanische Drama des 16. und 17. Jahrhunderts zählt mit Sicherheit zu den Höhepunkten der europäischen Theaterentwicklung. Umso erstaunlicher mutet es an, daß dieses Theater sozusagen aus dem Nichts entstanden sein dürfte: die dramatischen Texte, die uns aus dem Mittelalter erhalten geblieben sind, beschränken sich auf ein Fragment eines Weihnachtsspiels aus dem 12. und auf einige wenige geistliche und höfische Spiele aus dem 15. Jahrhundert. ${ }^{1}$ Selbst wenn sich aus historischen und juristischen Quellen (etwa den Siete Partidas Alfons' des Weisen) schließen läßt, daß es in gewissem Umfang doch eine wenigstens kirchliche Spieltradition gegeben haben muß, so ist klar, daß sie bei weitem nicht an Dichte und Niveau etwa der französischen Dramenproduktion herangereicht haben kann. ${ }^{2}$ Vor allem sind uns keine Hinweise auf eine einheimische Farcenoder Komödientradition überliefert. Das Theater ist daher um die Jahrhundertwende vom 15. zum 16. Jahrhundert eine völlig neue Realität, die erst ins Bewußtsein der Menschen dringen muß, für die etwa Begriffe wie "comedia" und "tragedia" noch nicht notwendigerweise mit in Dialogform sprechenden Schauspielern auf einer Bühne verbunden waren. ${ }^{3}$ Diese allmähliche Verankerung in der lebensweltlichen Realität erfolgt im Laufe des 16. Jahrhunderts, das unter starkem italienischen Einfluß steht (vor allem in Bezug auf das Hoftheater, aber auch auf das gelehrte Humanistentheater und später auf die volkstümliche Komödie, für die die commedia dell'arte eines der Vorbilder abgibt). Mit Lopes Generation, um die Jahrhundertwende zum 17. Jahrhundert, etabliert sich das spanische Theater dann in einer Weise, die es zum ersten wirtschaftlich organisierten Nationaltheater im modernen Sinn überhaupt werden läßt. Auch im Roman kann man in Spanien das Phänomen der wirtschaftlich orientierten Produktion von Texten einer "Modegattung" (Ritter-, dann Schäfer-, schließlich Schelmenroman) beobachten, das viel mehr den Gesetzen des Literaturmarktes

\footnotetext{
1 Ruiz Ramón, Francisco, Historia del teatro español..., ${ }^{2} 1971$, S. 13, spricht von einem "naufragio del que sólo se han salvado dos islotes". Tatsächlich haben auch gründliche Nachforschungen (wie etwa von R.B. Donovan, The Liturgical Drama in Medieval Spain, Toronto 1958) keine Ergebnisse gebracht. Das jüngst entdeckte Auto de la Pasión von Alfonso del Campo (vgl. González Ollé, "Die Anfänge des spanischen Theaters", in: Klaus Pörtl (Hg.), Das spanische Theater...) stammt erst aus 1487 und kann die Lücke zwischen den beiden "islotes" nicht schließen.

2 Vgl. dazu R. Hess, "Das religiöse Drama in der Romania" und "Das profane Drama in der Romania", in: E. Erzgräber (Hg.), Neues Handbuch der Literaturwissenschaft, Bd. 8: Europäisches Spätmittelalter, Wiesbaden 1978, S. 657-712.

3

war es ja im Mittelalter auch bei antiken Komödien (etwa von Terenz) üblich, dramatische Texte zu rezitieren und höchstens von maskentragenden Schauspielern pantomimisch begleiten zu lassen. - vgl. dazu J. Suchomski, M. Willumat, Lateinische Comediae des 12. Jahrhunderts, ausgewählt, übersetzt und mit Einleitung und Erläuterungen versehen, Darmstadt 1979, S. 16.
} 
zu folgen scheint, wie wir ihn aus dem 19. und 20. Jahrhundert kennen, als den zeittypischen ästhetischen Normen der Renaissance und des Barock, die durch die starke Rolle des Mäzenatentums und kleiner literarischer Zirkel im Frühabsolutismus geprägt waren. Die Ursache hierfür kann im sozioökonomischen Bereich gesucht werden: in der Gesellschaft vor allem Madrids, die quer durch die Stände von dem aus den Kolonien hereinströmenden Gold lebte, wenig produzierte und viel Zeit für Spektakel und Künste zur Verfügung hatte; ${ }^{4}$ in der finanziell und durch das Interesse der Gegenreformation am Propagandainstrument Theater begründeten Partnerschaft zur katholischen Kirche; wohl aber auch in der enormen Begeisterungsfähigkeit der Spanier für Schauspiele schlechthin, die um 1600 aber zu einer wahren Theatermanie führte. Das war nur möglich, weil dieses Theater zwar adelige Protagonisten und deren Wertvorstellungen auf die Bühne brachte, daneben aber im gracioso eine durchaus ebenbürtige volkstümliche Gegenfigur schuf, ${ }^{5}$ die in ihrer kontrastiven Partnerschaft mit den Herrenfiguren auf der Bühne Spiegel der Partnerschaft im Publikum zwischen den gefürchteten "mosqueteros" aus dem Stehparterre und den großen Herren in den Logen war. Erst um die Mitte des 17. Jahrhunderts führte dann das Palasttheater, das Volk ausschließend, das spanische Drama zu seinen Wurzeln im höfischen Fest zurück, während nur die musikalische Komödie in Form der zarzuela als bescheidene Nachfolgerin der großen Epoche des Volkstheaters verblieb. Diese Entwicklung soll hier in groben Zügen und in ihren wesentlichsten Phasen nachgezeichnet werden.

\section{Ursprünge des spanischen Theaters: Höfisches Fest und Re- naissance-Ekloge in der Schule Juan del Encinas}

\subsection{Die Wurzeln des spanischen Theaters im Siglo de Oro}

Das um 1500 entstehende spanische Theater läßt sich auf wenigstens fünf Wurzeln zurückführen: auf die liturgische Darstellung, auf das höfische Fest, auf Dialoggedichte in mittelalterlicher oder antiker Tradition, auf die gelehrte (und v.a. zur Vorlesung bestimmte) Humanistenkomödie und schließlich auf die volkstümliche Farce, die allerdings erst durch den italienischen Einfluß der commedia dell'arte-Tradition theaterfähig geworden sein dürfte. In der ersten Generation

\footnotetext{
${ }^{4}$ Vgl. dazu José María Diez Borque, Sociedad y teatro en la España de Lope de Vega, Barcelona 1978, vor allem Teil I: "Estructura económica, social y administrativa del espectáculo teatral".

5 Übrigens im Unterschied zur französischen Komödie des frühen 17. Jahrhunderts; in den Komödien Corneilles und seiner Generation sind die Protagonisten entweder ausdrücklich (z.B. Pierre Du Ryer, Les vendages de Suresnes) oder implizit durch ihren Wertehorizont (Geld als Wertmaßstab statt Abstammung, Kriegsruhm oder Ehre) als Bürger gekennzeichnet; die Dienerfiguren sind dort nur ansatzweise entwickelt. In der spanischen Konzeption kann man nun mit H.J. Müller, Das spanische Theater im 17. Jahrhundert oder zwischen göttlicher Gnade und menschlicher List, Berlin 1977, S. 12, eine "wahrhaft egalisierende Personenkonstellation" sehen, in der sich "das katholische Weltbild des Siglo de Oro" spiegle, dem zufolge "vor Gott alle Menschen gleich sind". Angesichts der ökonomischen Notwendigkeiten geht es aber wohl vor allem darum, für alle Schichten ein Identifikationsangebot bereitzuhalten, um so den Erfolg des Stückes sicherzustellen.
} 
von Theaterautoren, der mit dem Namen Juan del Encinas verbundenen Salmantiner Schule, haben wir es vor allem mit einer Verschmelzung der ersten drei Erscheinungen zu tun:

1) Schon im Mittelalter dürfte es in gewissem Umfang eine quasi-dramatische Darstellung neutestamentarischer Erzählungen (v.a. Weihnachten, Ostern) zur Verdeutlichung der Heilsgeschichte für Analphabeten gegeben haben (im Siglo de Oro sind dann von den Missionaren ähnliche Spiele für die amerikanischen Indios geschaffen worden): erhalten sind nur das Auto de los Reyes Magos aus dem 12. und eine dialogisierte Klage über die Passionsgeschichte von Gómez Manrique aus der Mitte des 15 . Jahrhunderts. ${ }^{6} \mathrm{Zu}$ Anfang des 16. Jahrhunderts verbindet sich diese Tradition mit der höfischen Festkultur zu höfisch-religiösen autos (Encina), mit dem Jesuitentheater zu autos, die für das Kirchenvolk bestimmt waren (z.B. jenen von Lucas Fernández), aus denen sich dann im Laufe des 16. Jahrhunderts u.a. die Form des auto sacramental entwickelt.

2) Die Dialoggedichte: Aus der mittelalterlichen Tradition ist das Streitgespräch (Poema de debate) als Gedichtform überliefert, sei es für sich stehend (Elena y Maria, Agua y vino) sei es in Form von eingeschobenen Dialogen in lyrischen oder erzählenden Werken (etwa im Libro de buen amor des Arcipreste de Hita). Aus der Kommunikationspraxis mittelalterlicher Literatur (mündlicher Vortrag vor Publikum) ergibt sich bei solchen Dialoggedichten eine paratheatrale Situation. Ein zum eigentlichen Theater überleitendes Spätprodukt dieser Traditionslinie ist z.B. Rodrigo de Cotas lyrischer Dialog Amor-Viejo aus dem späten 15. Jahrhundert. Dazu tritt nun durch die Renaissance das Dialoggedicht aus antiker und humanistischer Tradition, die Ekloge im Sinne von Vergils Bucolica. Vorbilder hierfür waren zahlreiche mittellateinische Eklogen, die bis in die karolingische Zeit zurückreichen, aber auch die italienische Eklogendichtung des 15. Jahrhunderts (Boiardo, Sannazaro) und die sich wachsender Beliebtheit erfreuende Schäferdichtung, die sich mit politisch-allegorischen Traditionen des Mittelalters verbinden kann wie in Francisco de la Madrids Égloga von 1495. Typisch ist dabei die enge Verbindung von Lyrik und Drama zu Beginn (erst Lucas Fernández führt in der Ausgabe seiner Werke die Trennung zwischen lyrischen und dramatischen Gedichten ein.)

3) Die höfische Festkultur hat ihren Ursprung in der Tradition mittelalterlicher Spiele (Turniere) und Sängerwettstreite sowie in Triumphzügen, die antiken Inszenierungen nachempfunden sind. Schon in der 2. Hälfte des 15. Jahrhunderts bringt sie mit Gómez Manriques Momos (einer Art Ballett-Pantomimen) erste dramatische Versuche hervor; sie wird vor allem durch das Vorbild der italienischen Renaissancefürstenhöfe geprägt.

\footnotetext{
${ }^{6}$ Eine vielfältige Spielkultur wie in Frankreich hat wegen des mozarabischen Ritus, in den sich theaternahe Formen der dargestellten Heilsgeschichte nicht einbauen ließen, in Spanien nicht bestanden, Mirakelspiele treten überhaupt erst im Siglo de Oro als comedias de santos auf.
} 


\subsection{Juan del Encina (1468-1529)}

Juan del Encina beginnt seine Karriere als Hofdichter und Festausstatter bei den Herzögen von Alba, später reist er nach Rom und ist dort an Kardinalshöfen tätig. Seine 14 dramatischen Eklogen entstehen zwischen 1492 und 1513 und werden schon zu seinen Lebzeiten in mehreren Werkausgaben (noch zusammen mit seiner Lyrik) veröffentlicht. Im gedruckten Text ist dabei der eigentlichen Ekloge stets eine kurze Prosabeschreibung des Anlasses der Aufführung (oft mit Fürstenlob) vorangestellt. Nach der (gewöhnlich im spanischen Achtsilber gehaltenen) Ekloge folgt am Ende ein gesungener villancico (eine traditionelle Liedform mit tanzartigem Charakter) und damit die Überleitung zum nächsten Programmpunkt des höfischen Festes.

\section{Schema der Eklogen von Juan del Encina}

1,2: Weihnachtseklogen

3,4: Ostereklogen: Passionsgeschichte

5,6: Eklogen zum Faschingdienstag/Aschermittwoch

7,8: Ecloga en recüesta de unos amores: Werben eines Knappen um eine Hirtin, Verkleidung als Schäfer, nach einem Jahr Rückkehr an den Hof

9: Weihnachtsekloge "de las grandes lluvias"

10, 12: italianisierende Eklogen: Liebeskranke Schäfer klagen ihr Leid

11: Allegorische Ekloge: Streit über die Berechtigung der Weltflucht, Entscheidung für Lebensgenu $ß$ im Sinne der Renaissance

13: "Auto del repelon": Satire des pastor bobo, der von den randalierenden Studenten Prügel bezieht

14: "Plácida y Vitoriano": italianisierende Ekloge erstmals in der Länge eines "abendfüllenden" Dramas; Neben neoplatonisch liebenden Schäfern tritt als Kontrastfigur wieder der pastor bobo auf.

Während die ersten vier Eklogen noch liturgischer Natur sind, weisen die Eklogen fünf und sechs nur noch eine äußerliche Beziehung zum Kirchenjahr auf, da sie am Beginn der Fastenzeit aufzuführen sind, der Inhalt ist dagegen teils politischer Natur (Konflikt mit Frankreich), teils eine Variation über das alte Thema der Schlacht zwischen Carnal (Karneval) und Frau Cuaresma (Fastenzeit). Die vermutlich zum Jahresausklang gespielten Dialoge sieben und acht lösen sich vollends vom kirchlichen Festkalender. Inhaltlich schließen sie an die lyrische Tradition der mittelalterlichen Pastourelle an, die ebenfalls stark dialogisch geprägt war. In der Behandlung des für die Bukolik konstitutiven Gegensatzes zwischen Hof und Land wird letztlich dem Hof der Vorzug gegeben, aber schon die für die Schäferliteratur typische Verkleidung von Höflingen als Hirten angedeutet. In der Gestalt des Mingo finden sich zudem erste Elemente der komischen Hirtenfigur, aus der später der pastor bobo und damit einer der Ahnherren des gracioso wird. Dieser Typus wird vor allem in der Ekloge 13, dem sogenannten Auto del repelón weiterentwickelt, in dem die naiven Hirten von den schlauen Studenten hinters Licht geführt und verprügelt werden.

${ }^{7}$ Zu Juan del Encina vgl. auch hier: K. Kohut, Das 15. Jahrhundert, S. 63f, sowie G. Güntert, Siglo de Oro: Lyrik, Teil I, S. 119f. 
Die Eklogen 10, 12 und 14 stehen dagegen in der Tradition des italienischen Schäferspiels, in dem Amor die Hirten seine Macht spüren läßt und Liebe zu Leid und bisweilen sogar zum Selbstmord führt, aber auch hier ergänzt der spanische "pastor bobo" das Personenrepertoire. Die letzte Ekloge (Plácida y Vitoriano), die 1513 in Rom aufgeführt wurde, vollzieht (schon allein von der "abendfüllenden" Länge her) endgültig den Schritt vom höfischen Spiel zum Schäferdrama. Hier findet sich neben dem Hirten- und Liebesinventar der Prolog einer "niederen" Figur (des Korbflechters Gil) mit einer Inhaltsangabe des Stückes wie bei dem zur gleichen Zeit in Rom weilenden Torres Naharro; es gibt eine Kupplerin und Szenen im Dienermilieu wie zuvor in der Celestina sowie realistische Genreszenen, wie sie im italienischen Bereich nur bei dem parodierenden Ruzante denkbar wären. Vieles ist auch bei Encina Parodie: Als Vitoriano die Selbstmörderin Plácida findet, spricht er ein blasphemisches Gebets-Pastiche, gerichtet an Amor/Cupido: erst eine Vigilie mit lateinischen Brocken als Villancico, dann Psalmen als Gebet mit dem Schlußestribillo: "Pater noster, niño y ciego,/ a tí digo, dios de amor" und schließlich "Lecciones": "Cupido, kirieleyson/ dina Venus, Christeleyson/ Cupido, kirieleyson", und dieses blasphemische Gebet bewirkt tatsächlich die Auferweckung des Mädchens. Bedenkt man, daß dieses Stück an einem Kardinalshof aufgeführt wurde, sieht man, wie frei das Rom der Renaissance unter den weltlichen Genüssen nicht abgeneigten Päpsten wie Julius II. und Leo X. im Umgang mit religiösen Fragen gewesen ist. Somit erweist sich Juan del Encina zwar wie fast jeder in Hofdiensten stehende Renaissancedichter als Mann der "Ordnungsmächte"; aber sein Werk zeigt zugleich auf, daß diese Ordnungsmächte zu Beginn des 16. Jahrhunderts offenbar gehörig in Unordnung geraten waren und daher weitgehende Freiheiten im Umgang mit ihren Dogmen und Prinzipien zugestanden.

\subsection{Lucas Fernández (1474?-1542)}

Die 1514 veröffentlichten dramatischen Werke von Lucas Fernández, der ebenfalls zwischen 1496-98 im Dienst des Duque de Alba steht und später die von Encina angestrebte Kantorsstelle in Salamanca erhält, haben thematisch und strukturell, aber auch in der Sprache viel mit Juan del Encinas Eklogen gemeinsam: beide verwenden den sogenannten "sayagués", einen literarischen Kunstdialekt, basierend auf dem Dialekt der Gegend von Salamanca. Wie Encina hat Fernández zwei Weihnachtseklogen verfaßt, weiters ein Auto de la pasión, sein bekanntestes Werk, das zum Unterschied von Encinas Eklogen mit Sicherheit nur für die Aufführung im Kirchenraum, während der Karfreitagsliturgie, gedacht war, und schließlich drei farsas o cuasi-comedias mit den stehenden Figuren Bras und Juan. Diese farsas bringen, offenbar angeregt von der Lektüre antiker Komödienautoren (Terenz und/oder Plautus), einige traditionelle Komödienfiguren in das spanische Theater ein: so den "bösen Alten", der die

\footnotetext{
${ }^{8}$ Schoell, Konrad, in: V. Roloff, H. Wentzlaff-Eggebert (Hg.), Das spanische Theater..., S. 12.
} 
Hochzeit des verliebten Schäferpaares aus materiellen Interessen (Abstammung und Geld) verhindert, oder den "miles gloriosus", der im Wortgefecht gegen den "pastor" unterliegt. Dadurch stellen Fernández' farsas den ersten Ansatzpunkt zu einer spanischen Komödie im engeren Sinn dar.

\section{Die Tradition der Humanistenkomödie}

Die in Italien und Frankreich sehr beliebte lateinische Humanistenkomödie mit profanen Themen ist in Spanien erst nach dem Erfolg der in Spanisch verfaßten Celestina anzutreffen (das erste Werk dieser Gattung, Juan Maldonados Hispaniola, stammt von 1517). Die spanische Produktion ist jedoch sehr früh durch die Celestina (eigentlich Tragicomedia de Calisto y Melibea) ${ }^{9} \mathrm{zu}$ Weltruhm gelangt. Dabei handelt es sich um eine Art Stück ohne Bühne, der Text gibt keine Hinweise auf die Aufführungstechnik, das Publikationsdatum der ersten Version (1499) zeigt, da $\beta$ es in eine Welt hineingestellt wurde, die über kein Theater im heutigen Sinne, kein theatererfahrenes Publikum, keine Truppen, keine bekannten Komödientypen verfügte. Aber auch mit dem höfischen Fest hat die Celestina schon vom Thema her wenig zu tun. Zahlreiche Indizien deuten auf einen Lesevortrag mit verteilten Rollen in einem gebildeten Freundeskreis hin (besonders der Kommentar des Herausgebers Alonso de Proeza zu der Ausgabe von 1514 - "dize el modo que se ha de tener leyendo esta comedia"). ${ }^{10}$ Die Autorenschaft ist umstritten, das Akrostichon der Eingangscoplas gibt den "bachiller Fernando de Rojas" an, der in seinem Vorwort allerdings betont, er habe nur die Fortsetzung zu dem bereits existierenden ersten Akt (vermutlich um 1490 entstanden) verfaßt, für den als mögliche Autoren u.a. Juan de Mena und Rodrigo de Cota genannt wurden. Als Zweck seines Werkes bezeichnet der Autor die Abschreckung der Jugend von den Gefahren der Liebe, ${ }^{11}$ als Gewährsmann für die Form der "comedia" (wie die Celestina in der Version von 1499 hieß) den römischen Autor Terenz. Die Umgestaltung zur "Tragicomedia" (um 1500) stützt sich auf eine Tradition der lateinischen Humanistendichtung und sollte als Gattungsmischung die Dramenpoetik des Siglo de Oro noch nachhaltig bestimmen.

\section{Die drei Teile der Celestina}

1) 1. Akt: Calisto, ein vornehmer junger Mann, dringt bei der Verfolgung eines Falken in Pleberios Garten ein, spricht dort mit dessen Tochter Melibea und verliebt sich unsterblich in sie, wird aber abgewiesen. Als er daraufhin liebeskrank wird, rät ihm sein Diener Sem-

\footnotetext{
9 Zur Celestina vgl. auch hier: K. Kohut, Das 15. Jahrhundert, Kapitel 5, S. 74ff.

${ }^{10}$ Demzufolge wurde die Celestina im 16. und 17. Jahrhundert als Drama, im von der Klassik geprägten 18. und 19. Jahrhundert als Dialogroman angesehen. Erst seit Maria Rosa Lida de Malkiels La originalidad artística de La Celestina, Buenos Aires ${ }^{2} 1970$ ist die Zugehörigkeit zur dramatischen Gattung eindeutig nachgewiesen und anerkannt.

${ }^{11}$ Diese "moralisch-didaktische" Intention läßt sich freilich ebenso in Frage stellen wie etwa die des Arcipreste de Hita im Libro de Buen Amor. So sieht etwa Albert Gier in: V. Roloff, H. WentzlaffEggebert (Hg.), Das spanische Theater..., S. 33, m.E. zu Recht auch eine gewisse "Sympathie oder Bewunderung" des Autors für Calistos "romantische Leidenschaft".
} 
pronio, der stets das eigene Wohl im Auge hat, die alte Kupplerin, Bordellmutter und Hexe Celestina zu konsultieren. Der treue Diener Pármeno rät vergeblich ab und versucht, die Alte fernzuhalten. Calisto schenkt ihr 1000 Golddukaten, sie verspricht, für ihn zu arbeiten.

2) Akt 2-16 der ersten Version (Comedia, 1499): Celestina gelingt es durch Teufelsbeschwörung, Melibea zu einem Stelldichein mit Calisto zu bewegen, sie schließlich sogar ihrerseits liebeskrank zu machen; die Kupplerin zeigt dabei jedoch auch menschlich-kreatürliche Schwächen (Angst). Nun wollen die Diener (Pármeno hat mittlerweile seinen Widerstand aufgegeben) auch ihren Anteil an der Belohnung, bringen die Alte im Streit um und werden dafür unverzüglich hingerichtet. Bei einem nächtlichen Stelldichein fällt Calisto von der Mauer und bricht sich den Hals. Die verzweifelte Melibea bekennt vom Turm herab den Eltern ihre Liebe und stürzt sich zu Tode.

3) 2. Version (Tragicomedia, Erstdruck 1507): Zwischen den Tod der Celestina und den Calistos werden fünf Akte eingeschoben, die möglicherweise von einem dritten Autor stammen: zwei Insassinnen des Bordells, die ehemaligen Freundinnen der Diener, wollen gemeinsam mit einer Gaunerfigur ("rufián") namens Centurio den Tod der Drei rächen und führen Calistos Tod bei dem Stelldichein, dem nun ein ganzer Monat nächtlicher Liebestreffen vorausgegangen ist, durch einen Überfall herbei.

Die wesentliche Neuerung der Celestina besteht in der Einführung "unliterarischer", realistisch gezeichneter Figuren aus dem Volk (im Gegensatz zu den Hirten der Encina-Schule, deren "sayagués" einen Kunstdialekt darstellt, und die teils transponierte neoplatonische Liebende, teils zur Belustigung dienende "bobos" sind). Die Sprache dieser "niederen" Figuren ist voll humanistischen Bildungsgutes, zugleich aber auch recht derb. Die neuere Forschung hat jedoch gezeigt, daß auch die Dialoge der "niederen" Figuren nicht einer realistischen Darstellung, sondern einer möglichst großen Variation rhetorisch fundierter Argumentationsstrategien dienen. ${ }^{12}$ Im großen und ganzen drückt sich in der Celestina aber wohl (ähnlich wie in den Komödien Machiavellis) vor allem ein skeptisches Menschenbild aus, das der Autor durch Beteuerung seiner moralistischen Absicht (im Untertitel: "contiene ... avisos muy necessarios para mancebos, mostrándoles los engaños que están encerrados en sirvientes y alcahuetas") nur oberflächlich zu mildern vermag.

Die enorme Nachwirkung der Celestina drückt sich darin aus, daß der Stoff praktisch sofort in Romanzen verarbeitet wird. Zahllose Stücke, von Torres Naharros Himenea bis zu einer Segunda (1534), Tercera (1539) und Cuarta parte de la Celestina (1542) aus der Feder verschiedener Autoren bezeugen ebenso ihre Beliebtheit wie die Übersetzungen (italienisch schon 1506, deutsch 1520, englisch und französisch 1527, 1624 sogar lateinisch durch Kaspar von Barth). Trotz des Verbots durch den Inquisitionsindex bleibt diese Nachwirkung auch in den späteren Generationen erhalten; noch im 19. und 20. Jahrhundert finden sich zahlreiche Bühnenbearbeitungen, 1975 entsteht sogar eine deutsche CelestinaOper. $^{13}$

\footnotetext{
${ }^{12}$ A. Gier in: V. Roloff, H. Wentzlaff-Eggebert (Hg.), Das spanische Theater..., S. 27.

${ }^{13}$ Siehe zum Nachleben der Celestina Eberhard Leube, Die "Celestina", München 1971, S. 53-57 und Dietrich Briesemeister, "Die Sonderstellung der 'Celestina'", in: Klaus Pörtl (Hg.), Das spanische Theater..., S. 101.
} 


\section{Die weitere Entwicklung vom höfischen Spiel zum Theater: Torres Naharro und Gil Vicente}

\subsection{Torres Naharro und die Sittenkomödie unter italienischem Einfluß}

Bartolome de Torres Naharro (ca. 1475-1520) stammt aus der Extremadura, aus Torre de San Miguel Sesmero (Provinz Badajoz). Von seiner Biographie ist kaum etwas Sicheres bekannt, um 1500 soll er zum Priester geweiht, kurz danach aber schon wieder Soldat geworden sein. Die oft tradierte Geschichte von einer kurzen Gefangenschaft in den Händen maurischer Piraten ist in der neueren Forschung angezweifelt worden. ${ }^{14} \mathrm{Ab}$ ca. 1503 lebt er hauptsächlich in Italien, zunächst in Rom. Dort gibt es in dieser Zeit, in der auch die meisten Päpste weltlichen Vergnügungen zugetan sind (vgl. die Ausführungen zu Juan del Encina), eine große spanische Kolonie (10.000 von insgesamt 60.000 Einwohnern waren Spanier, darunter viele conversos, auch der päpstliche Hofstaat umfaßte zahlreiche spanische Kirchenfürsten).

Noch in der Nachfolge der Salmantiner Schule von Encina, mit dem er in Rom um die Gunst der Kirchenfürsten wetteiferte, schreibt Torres um 1505 einen Dialogo del Nascimiento. Danach überwiegt der Einfluß der italienischen Renaissancekomödie, Nachwirkungen der Encina-Schule bleiben nur in den von bobo-Figuren gesprochenen Introitos spürbar - auch sprachlich durch Verwendung des sayagués. Der Autor steht im Dienst zweier Kardinäle, schließlich übersiedelt er 1517 zu Fabrizio Colonna nach Neapel, wo im selben Jahr die erste Ausgabe seiner Werke (Propalladia) mit dem berühmten "Prohemio" (der ersten spanischen Dramenpoetik) erscheint. Die Sammlung enthält sechs comedias: Seraphina (ca. 1509), Soldadesca (1510), Trophea (1514), Jacinta(1514/15), Tinelaria (1516), Himenea (1516). Später entstehen noch Calamita (1519) und Aquilana (1520?).

Das theoretische Werk: der "prohemio" zu "propalladia"

In diesem Vorwort findet sich die erste eigene Komödiendefinition der spanischen Literatur, die einerseits die eingangs erwähnte Unerfahrenheit seiner Zeit mit der Realität des Theaters zeigt, andererseits bereits auf die Gattungsmischung der Schule Lope de Vegas vorausweist: "comedia no es otra cosa sino un artificio ingenioso de notables y finalmente alegres acontecimientos, por personas disputado."15

Bezüglich Struktur und Aufbau des Dramas hält Torres an der aus der Antike stammenden Fünfaktigkeit fest (bei Lope wird die Dreiaktigkeit üblich), aber er führt schon die später übliche Bezeichnung Jornadas für die Akte ein. Er fordert eine Personenzahl zwischen sechs und zwölf, gibt aber gleich zu, in der Tinelaria

\footnotetext{
${ }^{14}$ Vgl. Joseph Gilliet, Torres Naharro and the Drama of the Renaissance, Philadelphia 1961 (Hg. Otis H. Green), S. 404.

${ }^{15}$ Bartolomé de Torres Naharro, "'Prohemio' zu 'Propalladia'", in: Federico Sánchez Escribano, Alberto Porqueras Mayo (Hg.), Preceptiva dramática española..., S. 63-65.
} 
selbst dagegen verstoßen zu haben. Im Sprechen und Handeln dieser Personen sei die ständische Gliederung zu beachten. Schließlich unterscheidet er zwei Untergattungen der Komödie: die reale oder historische Fakten darstellende comedia a noticia ("de cosa nota y vista en realidad de verdad") und die fiktionale comedia a fantasía ("de cosa fantástiga o fingida, que tenga color de verdad aunque no lo sea").

\section{Das dramatische Werk: Torres' wichtigste Komödien}

Allen seinen Stücken ist ein Introito/Argumento vorangestellt, eine witzige und weitschweifige Einführung durch einen bobo-Typus in sayagués, in der oft auf den Anlaß der Aufführung angespielt wird, und die mit einer kurzen Zusammenfassung des Inhalts ausklingt. Es bildet eine Art Überleitung aus der lebensweltlichen Sphäre in die Bühnenrealität, die zeigt, daß es sich noch immer um ein für ein ganz bestimmtes Publikum konzipiertes höfisches Theater handelt. Der Introito weist aber auch auf die Loas des späteren Corral-Theaters voraus, die ebenfalls durch derbe Komik die Aufmerksamkeit des Publikums auf die Bühne zu lenken trachten.

Die comedias a noticia stellen Genrekomödien ohne eigentliche dramatische Handlung dar, die meist der satirischen Betrachtung eines bestimmten Milieus gewidmet sind. So führt die Soldadesca Szenen aus dem Leben arbeitsloser Söldner in Rom vor, wobei der Realismus sich mit farcenhaften Elementen wie Prügelszenen mischt, die sich etwa im Rahmen der Einquartierung von Söldnern bei römischen Bauern mit gegenseitigen Übertölpelungsversuchen oder des Schwindels der Hauptleute mit nichtexistenten Soldaten, deren Sold sie kassieren, ergeben. Die Hauptquelle der Komik bilden jedoch aus Verständnisschwierigkeiten zwischen Italienisch- und Spanisch-Sprechern resultierende Kommunikationsprobleme. Ähnliches gilt für die Tinelaria, die eine endlose Reihe von köstlich gezeichneten Schmarotzern in Küche und Haushalt der großen Herren (Kardinäle) vorführt, die nur betrügen und an ihren eigenen Vorteil denken, wobei auch hier viel Komik aus dem Sprachengemisch (Deutsch/Latein, Katalanisch, Französisch, Portugiesisch, Italienisch, Spanisch) und den entsprechenden Mißverständnissen entsteht. Die Moral für die zusehenden Kirchenfürsten wird im Introito gleich mitgeliefert: "para que aquí lo riáis/y en casa lo castiguéis". ${ }^{16}$

In den comedias a fantasía finden sich wie später bei Gil Vicente oft $\mathrm{Pa}$ rallelen zum Ritterroman. Die Comedia Himenea lehnt sich jedoch noch mehr an die Celestina an, vor allem in der Bedeutung der Diener als handelnde Figuren und in der Struktur der Handlung. Die Figur der Kupplerin selbst kommt freilich ebenso wenig vor wie der Liebestrank, außerdem gibt es ein happy end. In der Personenkonstellation (Liebhaber, Dame, eifersüchtiger Bruder als Hindernis) klingt bereits die comedia de capa y espada an. In ähnlicher Weise findet sich in der Aquilana bereits die Parallelführung von Herren- und Dienerhandlung, die später zu einem Topos des Siglo-de-Oro-Theaters wird: Aquilano

${ }^{16}$ Torres Naharro, Bartolomé de, Comedias, D.W. McPheeters (Hg.), Madrid 1973, S. 105. 
liebt die Königstochter Felicina, sein Diener Faceto ihre Zofe Dileta. Als komische Tölpel treten zwei Gärtner mit einer Vaterunser- und Beschwörungsparodie auf, die die Tendenz zur Hereinnahme des bobo aus dem isolierten Introito in die szenische Handlung selbst demonstrieren. ${ }^{17}$ Vom Standpunkt der Sozialgeschichte ist schließlich die Szene der Rollenumkehr von Interesse: Um Nachrichten über ihren Aquilano zu erfahren (der beim nächtlichen Rendezvous erwischt worden ist, sich aber als Erbprinz von Ungarn erwiesen hat und sie heiraten darf), muß Felicina kurzzeitig mit ihrer Zofe Rollen tauschen und deren Capricen erfüllen (vor ihr knien, Hand küssen, Schleppe tragen). Hier wird eine Aufwertung der Dienerfigur angedeutet, die auch in manchen besonders gebildeten gracioso-Figuren des späteren Theaters (etwa dem Turín in La verdad sospechosa von Ruiz de Alarcón) sichtbar wird.

\subsection{Gil Vicente: Hoftheater zwischen mittelalterlicher Tradition und Cha- rakterkomödie}

Gil Vicente (ca. 1480-ca. 1540) schreibt wie viele portugiesische Dichter seiner Zeit ganz oder teilweise in Spanisch (Kastilisch), das als Sprache der Gebildeten am Hof der portugiesischen Könige, an dem er als Hofdichter tätig ist, großes Ansehen genießt. Von seinen 46 Bühnenwerken (überliefert in der 1562 von seinem Sohn Luis herausgegebenen Copilaçam) sind $19 \mathrm{ganz}$ in portugiesischer, 12 ganz in spanischer Sprache abgefaßt, 15 weisen gemischtsprachige Dialoge auf, in denen einige Personen Spanisch, andere wiederum Portugiesisch sprechen. Seine frühen Hirtendramen (1502ff.) weisen deutliche Einflüsse von Encina und Fernández auf, wie z.B. das Auto pastoril castellano. In weiterer Folge erschließt er dem religiösen Theater freilich auch ganz neue Stoffbereiche, z.B. in seinem Weihnachtsspiel Auto de la Sibila Casandra, das eine Verbindung zur antiken Mythologie herstellt. ${ }^{18}$ Dazu nimmt Gil Vicente Einflüsse des französischen mittelalterlichen Theaters (moralités) und der spätmittelalterlichen Totentanztradition auf, was besonders in den drei Autos das Barcas (1517-19) zum Ausdruck kommt. Sehr früh beginnt er neben dem religiösen Theater auch mit einfachen Intrigenkomödien (farsas), etwa dem Auto das Indias, in dem die untreue Ehefrau eines unheroisch-raffgierigen "Entdeckers" sich mit dem aus den Kolonien heimkehrenden Mann ebenso rasch wie heuchlerisch versöhnt oder der Farsa de Inês Pereira, in der die gebildete und anspruchsvolle Inês erfahren muß, daß ein dummer, aber nachsichtiger Ehemann besser ist als ein kluger Haustyrann.

\footnotetext{
${ }^{17}$ So sieht Nina Cox Davies ("Torres Naharro's comic speakers: Tinellaria and Seraphina", in: Hispanic Review 56, 1988, 139-155) auf den Spuren von John Lihani (Bartolomé de Torres Naharro, Boston 1979, v.a. S. 149) im Werk des Autors eine allmähliche "Hereinnahme" des bobo aus dem introito in eine immer stärker ausgestaltete und dramaturgisch aufgewertete Rolle in dem eigentlichen Dramengeschehen, wodurch er zu einem deutlichen Ahnherrn des gracioso würde.

${ }^{18}$ Teyssier, Paul, Gil Vicente..., S. 48, gibt hierfür eine italienische Quelle, den Ritterroman Guerino il Meschino, an, den Vicente in spanischer Übersetzung gelesen haben dürfte.
} 
Um 1521 beginnt Gil Vicente, prunkvollere Ausstattungsstücke zu verfassen, da der Hof offenbar nun raffiniertere Schauspiele verlangt. In der an den König Joâo III gerichteten Carta-Prefácio zu Don Duardos (1522) erklärt Gil Vicente auch programmatisch seine Absicht, nunmehr kunstvoller und in höherem Stil schreiben zu wollen. Die Stoffe für diesen neuen Dramentypus bezieht er aus den in Blüte stehenden Ritterromanen (z.B. Don Duardos 1522, Amadís de Gaula 1523) und aus der antiken Mythologie (z.B. Templo de Apolo, 1526).

In Gil Vicentes Werk ist somit nicht nur eine starke Erweiterung der Thematik des noch jungen Hoftheaters, sondern vor allem auch eine bedeutende Interaktion mit anderen literarischen Gattungen und Traditionen zu beobachten. Er etabliert zahlreiche Komödientypen: Kupplerin, unwürdige Kleriker, dumme Bauern, unfähige Ärzte, usw., wie sie später in pasos und entremeses als lächerliche Figuren auftauchen, aber auch das mythologische Festspiel am Hof mit aufwendigem technischen Apparat, wie es in Spanien noch der späte Calderón pflegen wird. Schließlich weist auch bei ihm die Gattungsmischung (hohes und niederes Personal, teils ernste, teils komische Handlung mit happy end) bereits auf Lopes Dramenkonzeption voraus. ${ }^{19}$

\subsection{Die übrige dramatische Produktion der ersten Hälfte des 16. Jahrhunderts}

Die restliche dramatische Produktion dieser Zeit hat eher geringe Bedeutung, es handelt sich meist um Imitationen der zuvor genannten Autoren. Der Códice de Autos viejos gibt einen Überblick über diese Produktion meist anonymer Stücke, bei denen das religiöse Theater noch vorherrscht. Der bedeutendste Autor ist Diego Sánchez de Badajoz (gestorben um 1550) dessen 22 vorwiegend religiöse Werke 1554 postum als Recopilación en metro veröffentlicht werden. Viele dieser Stücke sind nun nicht mehr für Weihnachten oder Ostern, sondern für Fronleichnam bestimmt, zudem führt Sánchez de Badajoz in großem Umfang Allegorien ein und wird somit zu einem der wesentlichsten Vorläufer des auto sacramental. Wie Torres Naharro verwendet auch er eine Eingangsszene im burlesken Ton, um die Aufmerksamkeit des Publikums auf das Bühnengeschehen zu lenken; die ebenfalls religiösen farsas stehen dem komischen Theater Gil Vicentes nahe.

Darüber hinaus sind durch den Inquisitionsindex von 1559 und das damit verbundene Aufführungs-, Verbreitungs- und Leseverbot vermutlich viele interessante Dramentexte aus der ersten Hälfte des 16. Jahrhunderts verlorengegangen.

\section{Der Beginn des kommerziellen "Volkstheaters" mit Lope de Rueda (1509?-1565)}

$\mathrm{Ab} 1535$ besuchen italienische Theatergruppen Spanien, teils mit einem commedia dell'arte-Repertoire, teils mit Renaissancekomödien. In einer dieser Truppen lernt Lope de Rueda das Handwerk, ehe er ab 1540 oder 1545 mit seiner eigenen

${ }^{19}$ Zu Gil Vicente vgl. auch hier: G. Güntert, Siglo de Oro: Lyrik, Teil I, Kap. 1, S. 121f. 
wandernden Theatertruppe durchs Land zieht. So wird er zum ersten BerufsTheaterunternehmer Spaniens. Die einfache Bühnenausstattung dieser Zeit beschreibt Cervantes im Vorwort zu Ocho comedias y ocho entremeses als vier im Quadrat aufgestellte Bänke mit vier bis sechs darübergelegten Brettern, dazu eine an Seilen von links nach rechts zu ziehende alte Decke, hinter der die Musiker standen. ${ }^{20}$ Lope de Ruedas Repertoire bestand aus Prosa-Übertragungen italienischer Renaissancekomödien, die oft auf Novellenstoffen (Boccaccio, Bandello) beruhten. Seine Komödien sind mehr Nachdichtungen als eigenständige Schöpfungen, seine Neuerungswirkung beruht daher vor allem auf der Schaffung einer Bühnenprosa, auf der praktischen Theaterarbeit und auf den eingeschobenen Zwischenspielen (pasos). Lope de Rueda war als Schauspieler berühmter denn als Autor, seine Paraderollen sind Gauner, Tölpel und Negerinnen und allgemein die Dienergestalten, denen deshalb auch die besondere Liebe des Autors Lope de Rueda gilt, während die Charaktere seiner Protagonisten nicht sehr ausgeführt sind.

Die pasos sind kurze Zwischenspiele, meist mit einem oder mehreren gegenüber Encinas Schule weiterentwickelten bobos. 1567 gibt Juan de Timoneda postum die erste Ausgabe von Lope de Ruedas Komödien heraus (Eufemia, Armelina, Los engañados und Medora, zwei "coloquios pastoriles", Camila und Tymbria, sowie eine Ausgabe von sieben pasos unter dem Titel El deleitoso), 1570 veröffentlicht er im Registro de representantes weitere drei Pasos. Dort findet sich auch ein Hinweis auf Verwendung der pasos - wie die lazzi der italienischen commedia dell'arte sind sie an beliebiger Stelle einsetzbar, um lange Stücke kurzweiliger zu gestalten - zu Beginn, als Ausklang oder als Zwischenspiele, und sie lassen sich mit den verschiedensten Stücken kombinieren. Auch innerhalb der Stücke gibt es "paso-artige" Szenen, die dramaturgisch nicht nötig sind und nur lose mit der Handlung zusammenhängen, aber der Unterhaltung des Publikums durch komische Figuren dienen. Insgesamt sind uns zehn eigenständige und vierzehn in die Komödien eingeschobene pasos erhalten. Die Themen sind farcenhaft, oft Betrügereien, manchmal mit volkstümlichem Einschlag (La tierra de Jauja). Am bekanntesten ist der paso Las aceitunas, in dem eine Familie in einen handgreiflichen Streit über die Frage gerät, zu welchem Preis die frühestens in 20 Jahren zu erwartenden Früchte eben erst gepflanzter Olivenbäume verkauft werden sollen.

Aus der Form des paso entwickelt sich später der entremés und die ganze Palette der dramatischen Kleinformen des Siglo de Oro. Noch wesentlicher ist Lope de Rueda aber im "praktischen" Bereich: mit ihm etablieren sich die umherziehenden Theatertruppen als professionelle Organisationsform.

\footnotetext{
${ }^{20}$ "No había en aquel tiempo tramoyas, [...] no había figura que saliese de la tierra por lo hueco del teatro, al cual componían cuatro bancos en cuadro y cuatro o seis tablas encima, con que se levantaba del suelo cuatro palmos; [...] El adorno del teatro era una manta vieja tirada con dos cordeles de una parte a otra, que hacía lo que llaman vestuario, detrás de la cual estaban los músicos, cantando sin guitarra algún romance antiguo." (Cervantes, Obras completas, Angel Valbuena Prat

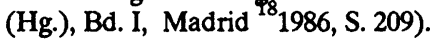


In der Nachfolge Lope de Ruedas schreibt in Valencia in dieser Zeit sein Herausgeber, der Buchhändler und Verleger Juan de Timoneda (1520?-1583) kurze komische Stücke, vor allem aber religiöses Theater: Ternarios Sentimentales (1. Bd. 1558, 2. 1575). Der 1. Band, der sechs Einakter über die Eucharistie enthält, stellt nach Wardropper den "Schlüssel für den Wandel von der "farsa sacramental anónima" zum "auto sacramental precalderoniano" dar; tatsächlich weisen die kurzen Stücke (z.B. Aucto de la Fee, 400 Verse) sowohl in der Verwendung von Allegorien (Glaube, Vernunft, Gerechtigkeit; Welt und Mensch) als auch in der Behandlung des für die Fronleichnamsliturgie zentralen Eucharistie-Themas auf diese wichtigste religiöse Theatergattung der Blütezeit voraus. $^{21}$

\section{Die Generation der Tragödienautoren (ca. 1575-1585)}

Nach der Etablierung des Theaters als wirtschaftlich organisiertes Schauspiel auch außerhalb der Hofgesellschaften kommt es zunächst (vor allem in den großen Theaterstädten Madrid und Valencia) zu einer Blütezeit der Tragödie, deren Ursprünge in humanistischen Versuchen zu finden sind, die antike Tragödie (v.a. Senecas) nach Spanien zu bringen. Das wichtigste Werk in diesem Kontext ist die anonyme Tragedia de San Hermenegildo über den Vater/SohnKonflikt zwischen dem heidnischen Gotenkönig Leovigildo und dessen getauftem Sohn Hermenegildo.

\subsection{Die Tragödienautoren}

Die bedeutendsten Tragödienautoren dieser Blütezeit der Tragödie sind:

- der um eine streng klassische Form (fünf Akte, Chor) bemühte Jerónimo Bermúdez (Madrid, 1530?-1599) mit seinen Tragödien Nise lastimosa und Nise laureada;

- Andrés Rey de Artieda (Valencia, 1544-1613) mit Los Amantes (1581), wo sich im Vorwort eine Absage an die Antike findet (Da Spanien großjährig ["en su edad robusta"] sei und in Sprachkunst wie Waffenhandwerk gleichermaßen mächtig, müsse es auch frei sein, seinen eigenen Geschmack zu entwickeln); tatsächlich entsteht hier die Tragödie ohne mythologische "Verursacher", nur durch menschliche Leidenschaft in einem zeitgenössischen Ambiente;

- Cristóbal de Virués (Valencia, 1550-1609), wie Cervantes ein Veteran der Schlacht von Lepanto, der in seinen Tragödien, wie später in Frankreich Alexandre Hardy, eine Vorliebe für menschliche Monster und Verbrecher zeigt (z.B. La gran Semiramis, La cruel Casandra, Atila furioso);

- und schließlich Juan de la Cueva (1550-1610), der nicht nur Dramatiker war, sondern auch Epen, Eklogen und v.a. die Poetik Ejemplar poético (1606) verfaßt hat. Seine dramatischen Werke umfassen neben Tragödien auch Tragikomödien; am bekanntesten ist El infamador, der als eines der Vorbilder für Tirsos Don

${ }^{21}$ Bruce W. Wardropper, Introducción al teatro religioso del Siglo de Oro, Madrid 1967. 
Juan-Stück El burlador de Sevilla gilt und die in der Gegenwart spielende Geschichte eines Wüstlings mit mythologischem Inventar (Götterfiguren, Allegorien) vermischt.

\subsection{Ein Dramatiker zwischen den Generationen: Miguel de Cervantes Saavedra} (1547-1616)

Neben seinen bekannteren erzählerischen Werken hat Miguel de Cervantes ${ }^{22}$ sich stets mit besonderer Liebe dem Theater gewidmet. ${ }^{23}$ Die erste der beiden Phasen seiner dramatischen Produktion in den 80er Jahren steht unter dem Einfluß der Generation der Tragödienautoren. Aus dieser Zeit sind uns die Stücke El trato de Argel und El cerco de Numancia erhalten, wobei vor allem letzteres als Spaniens wesentlichste klassische Tragödie angesehen wird. ${ }^{24}$

El cerco de Numancia, vermutlich 1583 entstanden, schildert in vier Akten den Heldenmut der "Spanier" in der von den Römern belagerten Stadt Numancia, die schließlich den Massenselbstmord der Kapitulation und Gefangenschaft vorziehen. In der Metrik herrscht der getragene Elfsilber vor, die Achtsilber sind auf die wenigen Liebesszenen beschränkt. Allegorische Figuren (España, Duero, Guerra, Hambre, Fama) untermalen das Geschehen und weisen auf eine bessere Zukunft (Cervantes' Gegenwart unter Philipp II.) hin.

In den 90er Jahren des 16. Jahrhunderts zieht Cervantes sich nach eigener Aussage wegen der übermächtigen Konkurrenz des "monstruo de la naturaleza" Lope de Vega und seiner Schule vom Theater zurück. Zwischen 1600 und 1615 entstehen einige nicht mehr unmittelbar für die Aufführung geschriebene Stücke, 1615 veröffentlicht als Ocho comedias y ocho entremeses nuevos, nunca representados mit einem Prolog über Geschichte und Theorie des spanischen Theaters. Diese Sammlung umfaßt verschiedene auch von Lope gepflegte Gattungen: capa y espada, picaresca, comedia de santo, etc., sie übernimmt viel von der neuen Schule, setzt sich aber zugleich ironisch-selbstironisch mit ihren Normen auseinander, etwa wenn in La entretenida (einer comedia de capa y espada) der Konvention der mehrfachen Heirat am Schluß eine Absage erteilt wird, oder in der Theaterkritik in Pedro de Urdemalas:

Pedro de Urdemalas ist eine pikareske Komödie in drei Akten um eine volkstümliche Hauptfigur (eine Art Eulenspiegel). Das zentrale Thema ist das Verhältnis zwischen Theater und Lebensrealität. Dadurch kommt es auch zu Theater auf dem Theater, die Einheit der Handlung wird, anders als in der Lope-Schule, nicht respektiert.

1. Akt: Pedro stiftet als Ratgeber des dummen Alcalde Crespo zwei Ehen, wird dann auf Aufforderung des Zigeunerkönigs Maldonado selbst gitano, um die schöne Belica heiraten

\footnotetext{
${ }^{22}$ Zu Cervantes vgl. auch hier: Chr. Strosetzki, Der Roman im Siglo de Oro, Kap. 4, S. $91 \mathrm{ff}$.

${ }^{23}$ In letzter Zeit findet auch der Dramatiker Cervantes zunehmend Beachtung in der Kritik: vgl. etwa Robert Marrast, Miguel de Cervantès, dramaturge, Paris 1957; Joaquín Casalduero, Sentido y forma del teatro de Cervantes, Madrid 1966; schließlich Jean Canavaggio, Cervantès dramaturge. Un théâtre d̀ naître, Paris 1977 und Manuel García Martín, Cervantes y la comedia española en el siglo XVII, Salamanca 1980.

${ }^{24}$ Vgl. etwa Francisco Ruiz Ramón, Historia del teatro español..., S. 128.
} 
zu können und erzählt als "Aufnahmeprüfung" seine pikareske Lebensgeschichte. Belica träumt jedoch, adelig zu sein und verschmäht ihn.

2. Akt: Pedro betrügt eine hartherzige Witwe, die den Zigeunern kein Almosen gibt, indem er ihr als frömmelnder Blinder einen Besuch aus dem Fegefeuer ankündigt. Als Belica ihn zurückweist, hat er Verständnis dafür, weil auch er von Höherem träumt. Der ihr zufällig auf der Jagd begegnende König läßt sie um ein Rendezvous bitten. Zuvor aber kommt es zu einer Tanzaufführung vor dem Königspaar, in der nach einem grotesken Bauerntanz die Zigeuner auftreten. Als Belica strauchelt und der König sie aufhebt, läßt die eifersüchtige Königin sie einsperren.

3. Akt: Pedro als Bote aus dem Fegefeuer entlockt der Witwe ein "Lösegeld" für ihre Verstorbenen. Der Ritter Marcelo enthüllt, daß Belica in Wahrheit die Nichte der Königin ist. Pedro als Student betrügt Bauern um zwei Hühner, dann schließt er sich zufällig vorbeikommenden Schauspielern an ("als Schauspieler kann ich alles sein, auch König") Als der autor über die Lage der Theaterleute klagt, wendet sich Pedro um Hilfe an Belica, indem er ihr zu verstehen gibt, sie hätten beide ihr Ziel erreicht: sie wäre Prinzessin in der Realität, er König auf dem Theater. Seine Bitte, der König solle nur professionelle Schauspieler gutes Theater spielen lassen, wird gewährt, Pedro schickt daher das Publikum nach Hause, um hinter der Bühne dem Hof "wirklich gutes" Theater vorzuspielen und kündigt im Schlußmonolog für den nächsten Tag ein neues Stück ohne Schlußheirat an.

Die weiteren Dramentypen dieser Sammlung stehen trotz der Distanz von Cervantes zur Lope-Schule eher in deren Tradition. ${ }^{25}$ Noch wesentlicher als die comedias sind aber die entremeses, Zwischenspiele, die eine Weiterentwicklung der pasos darstellen; bei Cervantes werden sie zu einer eigenen Kleinkunstform wie die Novelle im Bereich der Erzählgattung (er verwendet teilweise auch Stoffe aus den Novelas ejemplares). Die sprachliche Form ist meist, wie schon bei Lope de Rueda, die Prosa. Die Verbindung zur europäischen Farcentradition und die pointenorientierte Struktur zeigt sich etwa in folgendem Beispiel:

\section{La cueva de Salamanca}

$\mathrm{Zu}$ Beginn erlebt man den rührenden Abschied eines Ehepaars mit - kaum ist er fort, wartet sie mit ihrer Zofe auf die jeweiligen Galane, einen Sakristan und einen Barbier. Zuerst kommt jedoch ein armer Student und bittet um Nachtlager, danach erscheinen die beiden Liebhaber mit einem Essenskorb. Plötzlich klopft der Ehemann an, der zurückgekehrt ist, weil ihm das Wagenrad gebrochen ist. Die zwei Galane verstecken sich im Keller, der Student bleibt. Er behauptet zaubern zu können (weil er in einer Höhle in Salamanca die Magie studiert hat) und beschwört die beiden Versteckten mitsamt ihrem Essenskorb als Teufel aus dem Kohlenkeller. Zum Schluß essen und singen alle gemeinsam.

Ab der Jahrhundertwende zum 17. Jahrhundert, d.h., mit dem endgültigen Triumph von Lope de Vegas comedia nueva, erreicht das spanische Theater des Siglo de Oro seine endgültige Form. An dieser Stelle soll daher in kleinen Exkursen ein Überblick über das Gattungsrepertoire, die Dramentheorie und die Theaterpraxis dieser Zeit gegeben werden.

${ }^{25}$ Daraus läßt sich wohl nicht unbedingt ableiten, daß Cervantes Lopes poetologische Vorstellungen voll übernommen hat, wie Franco Meregalli ["Para una perspectiva del teatro de Cervantes", in: Ramos Ortega (Hg.), Teoría y realidad..., S. 23-35] zu Recht feststellt. Auf der anderen Seite scheint mir die Behauptung eines "frontalen Gegensatzes" zum dominierenden Theatermodell der Zeit (J. Talens, N. Spadacchini in ihrem Vorwort zu Cervantes' El rufíán dichoso - Pedro de Urdemalas, Madrid 1986, S. 77 ) übers Ziel zu schießen, insbesondere, wenn daraus eine revolutionäre Wirkungsintention durch Verweigerung gegenüber der Konfliktpotential abbauenden Wirkung tatsächlich aufgeführter comedias abgeleitet werden soll. 


\section{Die Vielfalt der dramatischen Gattungen im 'Siglo de Oro'}

Die Aufführung einer comedia im Corral-Theater war stets ein Spektakel, das sich aus der Kombination mehrerer dramatischer Kurzformen mit dem eigentlichen Stück ergab. ${ }^{26}$ Die Einleitung erfolgte durch einen Prolog (Introito, Loa), der der "Einführung" in die Illusionswelt der Bühne dient und seinen Ursprung im höfischen Fest hat. Dort wurde an dieser Stelle der Anlaß der Aufführung (Festtage, Hochzeiten, usw.) genannt. Schon bei Torres Naharro ist dieser einführende Prolog einer komischen Figur, dem pastor bobo, übertragen worden. Neben der Einführung in die theatralische Fiktion schlechthin hatte dieser Introito-Sprecher auch eine Erläuterung der Handlung (eine kurze Inhaltsangabe) zum besseren Verständnis vorzutragen. Später kam diese spannungsfeindliche Technik aus der Mode. Schon López Pinciano lehnt sie 1596 in seiner Poetik ab.

Dagegen dient die Loa im Corral-Theater vor allem dazu, sich Ruhe zu verschaffen und die Aufmerksamkeit der lärmenden, nicht sehr disziplinierten $\mathrm{Zu}$ schauer allmählich auf die Bühne zu lenken. Dazu sind alle Mittel recht: derbe Späße, ein direktes Ansprechen des Publikums, usw. Das Publikum wird dabei nicht ohne Ironie als "ilustre senado", "generoso auditorio", "ilustre congregación" bezeichnet, auch Anspielungen auf Ort oder Anlaß der Vorstellung sind noch üblich. Carvallo lobt in seinem Cisne de Apolo 1602 die loa mixta, die alle vier Grundarten (Lob des Publikums, Inhaltsangabe, Bitte um Ruhe und Tadel der Ruhestörer) enthält. Die Entwicklung läuft vom Monolog zum Dialog, später auch mit Tanzbegleitung; im Palasttheater des 17. Jahrhunderts wird wie im höfischen Fest um 1500 v.a. wieder das Fürstenlob betont.

Zwischen den Akten findet sich nun ein entremés, die aus dem paso entstandene Hauptform des kurzen Spiels. Es stellt meist ein realistisch-burleskes Gegenstück zur Haupt-Comedia dar, das mit wenigen Figuren niedrigen Standes auskommt. Während die entremeses de enredo einen kleinen Streich inszenieren, verzichten die entremeses de costumbres y de carácter oft überhaupt auf eine zusammenhängende Handlung. An die Stelle des entremés tritt bisweilen eine jácara, ein ursprünglich volkstümliches, dem Bänkelsang entsprechendes Genre, das die Geschichte eines Anti-Helden erzählt und in extremem Gegensatz zur comedia steht. Sie kann auch statt der Loa eingesetzt werden. Die Entwicklung läuft hin zu einer komplizierteren Form, der jácara entremesada, die nicht bloß gesungen, sondern auch auf der Bühne dargestellt wird. An Formen wie der jácara zeigt sich im übrigen, daß die Bedeutung der Bühnenmusik im 17. Jahrhundert gegenüber der Lope-de-Rueda-Zeit besonders stark zunimmt. Die compañias haben zwei bis vier ständige Musikanten (Instrumente: Gitarre, Violine, Harfe, Oboe), alle Schauspieler müssen singen und tanzen können. Bis-

\footnotetext{
${ }^{26}$ Die Forschung hat sich in den 80 er Jahren wieder verstärkt diesen kombinatorisch verwendbaren Kleingattungen zugewendet. Vgl. etwa als Beispiel die Ausführungen von Hugo Laitenberger, "Ehre und Ehrenrache in den Zwischenspielen von Calderón", in: Angel San Miguel (Hg.), Calderón..., S. 95-113.
} 
weilen tritt an die Stelle der bisher genannten Zwischenspiele überhaupt ein baile, mit oder ohne Bezug zur Handlung, der sich auch mit dem entremés zu einem baile entremesado bzw. entremés cantado verbinden kann, das aus gesungenen Dialogen unter Verwendung volkstümlicher Romanzen, Lieder und Tänze besteht.

Üblicherweise nach dem Stück, manchmal auch zwischen den Akten, findet sich schließlich eine mojiganga, ursprünglich eine volkstümliche, groteske Maskerade, die in der Karnevalszeit, später aber auch im Rahmen der Weihnachtsund Fronleichnamsprozessionen üblich war, und die in einem allgemeinen, das Publikum einbeziehenden Tanz endete. Darüber hinaus waren am Schluß der Aufführung auch jacaras und bailes möglich.

Die längeren Formen, die von dieser Vielfalt an Vor-, Nach- und Zwischenspielen eingerahmt wurden, erscheinen demgegenüber weniger differenziert: Die Entwicklung des spanischen Theaters geht von Schäferspiel (Encina) und Renaissancekomödie über die volkstümliche Farce Lope de Ruedas und die Tragödie der Generation um 1580 in der Zeit Lope de Vegas hin zu einem comedia genannten Kontinuum, das reine Komödien (Intrigen- und Charakterkomödien, v.a. comedias de capa y espada, Mantel- und Degenstücke), Tragikomödien, historische Schauspiele (comedias históricas), Ehrendramen (dramas de honor), lyrische Dramen, Märtyrerdramen (comedias de santos), ja sogar Tragödien umfassen kann (etwa Lopes Ehrendrama $\mathrm{El}$ castigo sin venganza).$^{27}$ Darüber hinaus entwickelt sich im Laufe des 17 . Jahrhunderts eine spezifische Form des religiösen Theaters, das einaktige Fronleichnamsspiel auto sacramental, und das barocke Theaterfest, die fiesta mitológica (s.u., Kap. 10). All diesen Formen sind aber gewisse Strukturmerkmale gemeinsam, etwa der gracioso, die spezifische Form der komischen Dienerrolle, die auch noch im religiösen auto ihren Platz hat, und die lyrische (polymetrische) Sprache, die aus ihnen im eigentlichen Wortsinn "dramatische Gedichte" macht.

\section{Zur Theorie des spanischen Theaters}

\subsection{Die italienische Vorgeschichte}

Die Geschichte der europäischen Poetiken in der Renaissance ist zunächst eine Geschichte der humanistischen Rezeption antiker Dichtungslehren, die teilweise über die mittelalterliche Rhetorik vermittelt worden ist. $\mathrm{Zu}$ Beginn orientiert man sich an Horaz' Epistola ad Pisones und Plato. Ab 1508 beginnt der Siegeszug des Aristotelismus, der 1540-1600 in Italien eine Reihe von Kommentaren und eigenständigen Poetiken hervorbringt. Wichtige Fragen in diesem Zusammenhang waren:

1) Gattungstheorie: Bei Aristoteles wird von den dramatischen Gattungen nur die Tragödie behandelt, daher gebührt ihr der Vorzug. 2) Stil und Personal: Aus

\footnotetext{
${ }^{27}$ Menéndez Pelayo unterscheidet allein für Lope 18 (nach Themen gegliederte) Gruppen von Dramen - vgl. J.L. Alborg, Historia de la literatura española..., Bd. II, S. $295 \mathrm{f}$.
} 
der aristotelischen "Angemessenheit" folgert man die Beschränkung des Personals in der Tragödie auf Götter, Könige und Fürsten. 3) Die "drei Einheiten": Aus der Einheit der Handlung bei Aristoteles und der beiläufigen Erwähnung, daß Tragödien meist nicht länger als ein Sonnenlauf oder wenig darüber dauern, formen die italienischen Kommentatoren die Theorie der drei Einheiten (Ort, Zeit, Handlung). Für die Komödie wird Aristoteles "adaptiert", indem man auf die Komödienpraxis von Plautus und Terenz verweist: man fordert auch hier die drei Einheiten und eine "angemessene" Personendarstellung, die Unterschiede zur Tragödie betreffen nur die Themen und das Personal der Stücke. Die Vermischung von Tragödie und Komödie wird mehrheitlich abgelehnt.

\subsection{Die spanische Theoriediskussion}

Eigenständige Poetiktraktate treten in Spanien erst später auf als in Italien, sieht man von Torres' Vorwort zur Propalladia einmal ab. ${ }^{28}$ Ein Problem bildet die Terminologie: Der Begriff comedia wird verwendet für 1) Gegensatz zu tragedia; 2) für das Drama im allgemeinen; 3) für das "teatro nacional español", was in der Folge oft Tragikomödie im Sinne Lopes heißt. Um 1590 verfaßt Alonso López Pinciano den ersten, gemäßigt aristotelischen Dialogtraktat Filosofia antigua poética, veröffentlicht 1596; darin zeigt sich eine Vorliebe für die Tragödie, weil der Autor noch unter Eindruck der Generation der Tragödienautoren steht, es wird aber auch die Komödie gelobt. Pinciano vertritt durchaus originelle Ansichten (z.B. Freiheit bei den drei Einheiten), lehnt aber jede Gattungsmischung (Tragikomödie) ab. Der erste Apologet der Lope-Schule ist Luis Alfonso de Carvallo: In seinem Dialogtraktat El cisne de Apolo (1602) wird die Dramatik als höchste literarische Gattung gesehen, die comedia von heute nehme dabei Anregungen aus allen nur denkbaren "Blütenarten der Poesie" auf. ${ }^{29} \mathrm{Da}$ er stark von der platonischen Furor-Lehre beeinflußt ist, wird Carvallo von späteren Aristotelikern abgelehnt. Auch der bereits erwähnte Juan de la Cueva wendet sich in seinem Ejemplar poético (1606) mit dem Argument "Die Zeiten ändern sich" gegen die Nachahmung der Antike. Er verteidigt auch die Einführung von "reyes y dioses" in die comedia (gemischtes Personal). Lope de Vega selbst hat seine theoretischen Vorstellungen im Arte nuevo de hacer comedias en este tiempo (1609), einer wenigstens partiell ironischen Antwort an eine aristotelische Akademie in Versen, zusammengefaßt. Der Autor behauptet dort, er wäre ja gerne Aristoteliker, aber das Publikum gestatte es ihm nicht. In der Folge wird die Dreiaktigkeit für jedes Drama vorgeschrieben, es werden Regeln für eine (polymetrische) Versifizierung angegeben, ebenso Anweisungen zur Personenzeichnung, wobei Lope vor allem mit der Notwendigkeit der Spannung argumentiert. Die Einheiten werden zwar gerühmt, aber mit dem Geschmack des Publi-

\footnotetext{
${ }^{28}$ Für die spanische Dramentheorie ist immer noch aktuell die bahnbrechende Arbeit von Margarete Newels, Die dramatischen Gattungen in den Poetiken des Siglo de Oro, Wiesbaden 1959.

29 "de todos los géneros de flores que en la poesía se puede imaginar", Sánchez Escribano, Porqueras Mayo, Preceptiva dramática española..., S. 117
} 
kums wird der Verstoß gegen sie entschuldigt (Ausnahme: Einheit der Handlung). Das Motto scheint also zu lauten: "Erlaubt ist, was gefällt".

Danach dreht sich die Diskussion hauptsächlich um die Unterstützung oder Ablehnung Lopes bzw. seines Konzepts der "comedia nueva"; aber trotz heftiger Attacken der Aristoteliker wie Suárez de Figueroa und Cascales setzen sich in der Praxis Lopes Vorstellungen durch.

\section{Produktions- und Aufführungsbedingungen des Theaters im 'Siglo de Oro'}

Das spanische Theater ist eng mit der Kirche verbunden: Die Truppen bilden sich immer zu Fronleichnam (schon ab 1520), und vor allem im 17. Jahrhundert ist die festliche Aufführung eines auto sacramental, die durch die Gemeinden fürstlich bezahlt wird, die finanzielle Basis dieser Unternehmungen. Dazu kommt die Verbindung mit den Spielstätten (Höfen - corrales), die meistens Laienbrüderschaften gehören, welche mit dem Erlös Spitäler und Waisenhäuser finanzieren, so daß die Kirche immer am Theater wirtschaftlich partizipiert und daher bei aller moralischen Gegnerschaft Interesse daran haben mußte, es zu erhalten. Zudem ist das Theater ein wichtiges Mittel des religiösen Anschauungsunterrichts im Rahmen der Gegenreformation ebenso wie bei der Missionierung Lateinamerikas.

\subsection{Die Spielstätte}

Gespielt wird zu Beginn wie erwähnt in Höfen von Brüderschaften (cofradías), die Spitäler betreiben und Geld dafür brauchen. Ab 1570 gibt es fast überall in Kastilien solche festen Spielstätten, in Madrid zwei: den Corral de la Cruz und den Corral del Príncipe. Ein solcher corral bestand aus drei großen Teilen: der Vivienda ( $8 \times 10,5 \mathrm{~m},{ }^{30}$ Eingangshalle, Kasse, kleine Läden, Büros, Garderobe), dem Hof $(14 \times 7,5$ m, 110 Bänke à 3 Personen und viele Stehplätze, am Rand 3 gradas, überdachte Stufen; für Adel und Reiche darüber aposentos, an den umgebenden Hauswänden angebaute, manchmal auch mit diesen verbundene Logen) und der hölzernen, erhöhten und überdachten Bühne, 2,5 m hoch, 7,5 x 4,2 m. Der darunterliegende Hohlraum enthält Herrengarderobe und Requisitenraum, im späteren Hoftheater auch die Bühnenmaschinerie, im corral gibt es jedoch nur die tramoya, eine sackartige Leinwandpyramide, die drehbar war, verschiedene Schauplätze simulieren konnte und verborgenes Auf- und Abtreten ermöglichte, dazu eine einfache Falltür und Versenkung. Hinter der Bühne ist die Damengarderobe aufgebaut, darüber zwei Gänge, etwa für Turmszenen. Dazu kommen die Logen an der Rückwand, v.a. die cazuela für Frauen aus dem Volk: ein geschlossener Holzkäfig, 8,4 m lang, mit eigenem Eingang und einem apretador, der nachzudrängen hatte, um das Fassungsvermögen zu erhöhen. Später entstand darüber wegen großen Andrangs noch eine cazuela alta, dazwi-

${ }^{30}$ Die Zahlenangaben entsprechen dem Corral de la Cruz. 
schen lagen die "Staatslogen" für den Consejo de Castilla und die Madrider Ratsherren.

In der Levante (Valencia) bzw, in Andalusien (Sevilla) waren die Theater dagegen überdacht, die Beleuchtung erfolgte durch Fenster (Kerzenbeleuchtung war verboten, die Stücke beginnen daher - im corral wie im gedeckten Theater je nach Jahreszeit zwischen zwei und vier Uhr nachmittags). Diese überdachten Theaterbauten waren an italienische Vorbilder (Palladio) angelehnt und verfügten vor allem in Katalonien nicht über Stehplätze, was die ständische Gliederung etwas milderte.

\subsection{Die Organisation des Bühnenwesens}

Die administrative Theater-Hierarchie sah wie folgt aus: An der Spitze stand ein protector als oberster Herr und Richter; er läßt die compañias zu, genehmigt die Stücke nach Begutachtung durch die Zensur, ernennt die nachgeordneten Beamten und erstellt die Theaterordnung. Neben den administrativen Theaterbeamten (comisarios) fungieren als Ordnungsbeamten eigene alguaciles, von denen je einer in jedem corral mit seinem Gefolge auf der Bühne saß, um die Ordnung während der Vorstellung zu überwachen.

Die Schauspieler schließen sich in Truppen zusammen: vom Einmannensemble (bululú) bis zur compañia (16-20 Schauspieler) unter einem Theaterunternehmer (autor de comedias: Direktor, Regisseur, Dramaturg in einem, erwirbt die Stückrechte vom poeta und haftet für alles). Ab 1600 ist für eine compañia fija eine königliche Konzession erforderlich, die Zahl dieser Truppen wird mit acht, ab 1615 mit zwölf begrenzt. Daneben gibt es viele (zeitweise bis zu 300) compañías de la legua, die in kleineren Dörfern spielen - ab 1646 sind sie jedoch verboten. Die compañia fija umfaßt ca. 20 Mitglieder, die Schauspieler haben meist einen Jahresvertrag mit einer nach Rollenfach gestaffelten Bezahlung, der jeweils ab Ostern (dem Probenbeginn für das Fronleichnamsspiel) läuft. Neben autor und Schauspielern gehören zur Truppe ein Requisiteur (guardarropa), ein Billeteur (cobrador) und ein Souffleur (apuntador). Ab 1631 gibt es mit der cofradía de los representantes eine Art Sozialversicherung, sie ist auch für die compañias de la legua zuständig, sorgt für Mittellose und kann den autor zu Gagenfortzahlung bei Krankheit zwingen. Die Finanzierung erfolgt durch Beiträge des autor und der Schauspieler.

Getrennt von den Ausführenden agierte der poeta: Der Dichter konnte bei hoher Produktionsgeschwindigkeit vom Theater recht gut leben (deshalb die "Vielschreiberei"). Er verkaufte sein Stück mit allen Rechten an den autor, der es später drucken lassen konnte. Der poeta bekam in diesem Fall keine Tantiemen mehr, was zu mangelndem Interesse der Dramatiker an Buchausgaben und dadurch zu sehr fehlerhaften Drucken führte. 
Das Publikum umfaßt alle Bevölkerungsschichten ${ }^{31}$ - auch viele stellenlose Diener, einfache Handwerker, Tagelöhner, usw., da die Eintrittspreise sehr niedrig sind und kaum andere Unterhaltungsveranstaltungen angeboten werden. Gefürchtet waren vor allem die mosqueteros im Stehparterre mit ihren Pfeifkonzerten und Wurfgeschossen. Manchmal gab es sogar Stinkbombenattentate. Zugleich war das Theater aber auch ein gesellschaftliches Ereignis für Adel und Bürgertum in den Logen.

\subsection{Theatermaschinerie und Aufführungspraxis}

Schon die Tragödienautoren um 1580 verwendeten etliche technische Hilfsmittel. Das Palasttheater verfeinert dann vor allem die Geräusch- und Lichteffekte. Kompliziertere Hebeeinrichtungen, Versenkung und dergleichen für "Erscheinungen" und Effekte spielten besonders bei Privataufführungen am Hof (fiestas mitológicas) und im religiösen Theater eine Rolle, sonst waren sie zu teuer. Die Corral-Bühne hat zwei Seiteneingänge, manchmal dazu einen durch einen Vorhang verdeckten Mitteleingang; Balkon, Fenster, Fassade der Rückwand können einbezogen werden. Dazu gibt es bewegliche Dekorationsstücke aus bemalter Leinwand. Im Palasttheater findet sich bereits eine perspektivische, wesentlich kunstvollere Dekoration, bei den autos sacramentales ebenfalls. Dort ist sie allerdings auf mehreren Wagen (carros) aufgebaut, die zusammengeschoben die Spielstätte ergeben. Die Kostüme - teils Eigentum der compañia, teils der Schauspieler, vor allem bei den primeros actores - sind prächtig und teuer und machen einen Teil der Faszination des Theaters aus.

\section{Die Generation Lope de Vegas}

\subsection{Die "minores"}

Vorläufer und Arureger, teilweise auch Schüler Lopes war eine Gruppe von Autoren in Valencia um den Canónigo Tárrega. Dazu gehört etwa Guillén de Castro (1569-1630), bekannt vor allem durch seine beiden Cid-Dramen Las mocedades del Cid I und II, die Romanzenstoffe aus der Jugend des Cid behandeln und später Vorbild für Corneilles berühmtes Drama Le Cid wurden. Aber auch in Kastilien und Andalusien beginnen sehr bald Autoren, Lopes Dramenkonzeption zu übernehmen, etwa Antonio Mira de Amescua (1574-1644), dessen comedia de santo "El esclavo del demonio" von 1612 das Faust-Motiv des Teufelspaktes behandelt, oder Luis Vélez de Guevara (1579-1644), der Autor der novela picaresca El diablo cojuelo, der wie Lope eine Vorliebe für Romanzenstoffe zeigt (La serrana de la Vera). Der Priester José de Valdivielso (ca. 1575-1638) schreibt

\footnotetext{
${ }^{31}$ Siehe dazu (und auch $\mathrm{zu}$ der vorhergehenden Schilderung der administrativen Organisation und der sozialen Lage der Theaterschaffenden) José María Díez Borque, Sociedad y teatro..., die Materialsammlungen von J.E. Varey, Norman D. Shergold, (Comedias en Madrid 1603-1709. Repertorio y estudio bibliográfico, London 1989; Los arriendos de los corrales de comedias de Madrid 1587. 1719. Estudio y documentos, London 1987), sowie Josef Oehrlein, Der Schauspieler im spanischen Theater...
} 
nur autos sacramentales und comedias divinas, sein religiöses Theater ist aber viel volkstümlicher als das Calderóns, er verbindet realistische und allegorische Elemente (z.B. in El hospital de los locos). Luis Quiñones de Benavente (ca.1592-1651) schließlich ist der große Meister des entremés nach Cervantes (1645 erscheint seine Sammlung Joco seria). Der entremés wird bei ihm endgültig zum satirisch-moralischen Einakter, der nun ebenfalls gereimt ist; dargestellt wird entweder ein farcenhafter Streich ("burla": ein gracioso lenkt das Opfer ab, eine zweite Person stiehlt ihm Geld oder entführt seine Frau) oder ein realistisches Sittenbild.

\subsection{Lope Félix de Vega Carpio (1562-1635)}

Lope ist die prägende Gestalt der Theaterentwicklung im Siglo de Oro. Durch seine ungeheure Popularität bei allen Volksschichten macht er das Drama zur dominierenden Literaturgattung. Cervantes' Wort vom "monstruo de la naturaleza" zeugt ebenso von seiner Wirkung wie die volkstümliche Redensart "es de Lope", die heute ungefähr "das ist super!" lauten müßte. In seiner Jugend wegen Spottgedichten auf seine erste große Liebe Elena Osorio (Tochter eines autor, Ehefrau eines Schauspielers) aus Kastilien verbannt, lernt er in Valencia die dortige Dramatikerschule kennen, die auch während der Blütezeit der Tragödie die Komödie gepflegt hatte. In den folgenden Jahren, vor allem nach seiner Rückkehr nach Madrid (1595), entwickelt Lope sein Konzept der comedia nueva, das sich durch bewußte Gattungsmischung Tragödie-Komödie, v.a. auch im Stil und im Personenrepertoire, ebenso auszeichnet wie durch das Übergewicht der spannungsgeladenen Handlung gegenüber den Charakteren bei gleichzeitiger Handlungseinheit. Bei den Komödien im eigentlichen Wortsinn kommt dazu noch die Konvention der mehrfachen. Hochzeit am Schluß. In der comedia nueva gelangt auch die Dienerfigur des vorhergehenden Theaters im Typus des gracioso zu ihrer vollen Ausformung: der Diener ist nun eine Kontrastfigur zu seinem idealistischen, verliebten Herrn, die sich im Gegensatz zu dessen vergeistigten Liebesproblemen durch irdische Interessen wie essen, trinken und schlafen bemerkbar macht. Er ist jedoch nicht mehr als Tölpel gezeichnet wie der villano bobo, sondern mit einem gewissen Hausverstand begabt, oft sogar als Ratgeber wichtig für seinen Herrn. Dramaturgisch ist er einerseits Hauptträger der Komik, andererseits Mittler zum Publikum durch seine Apartes und die Möglichkeit der Identifikation, die er vor allem dem Stehparterre bietet. Die meisten graciosos tragen sprechende Namen, die an sich bereits eine komische Wirkung auslösen. ${ }^{32}$ Mit Lope vollendet sich auch die durchgehende Versifizierung des Dramas in ständig wechselnden metrischen Formen (Polymetrie).

Durch die erwähnte Gattungsmischung kann sich nun unter dem Begriff comedia wie erwähnt jede traditionelle Gattung von der Komödie über die Tragikomödie bis zur Tragödie verbergen. Angesichts der riesigen Zahl seiner Stücke

${ }^{32}$ Siehe dazu Barbara Kinter, Die Figur des Gracioso... 
läßt sich Lopes Werk, vor allem in diesem Rahmen, daher nur exemplarisch anhand einiger weniger Dramentypen erörtern:

1) Ehrendrama (Mischung Tragödie/Komödie): Viele dieser Stücke lassen sich auf ein Dreiecksschema der Macht zurückführen: Der guten, ehrlichen Landbevölkerung steht ein ungerechter Feudalherr gegenüber, der sich meist sexuelle und damit gegen die Ehre gerichtete Übergriffe erlaubt; in diesen Konflikt greift ein rettender König ein, der den Feudalherrn bestraft. Ideologisch bildet bei Lope den Hintergrund dieses Schemas wohl der beginnende Absolutismus mit seiner Tendenz zur Einschränkung der Feudalrechte, wobei der König ein Bündnis mit dem "Volk" gegen den Adel sucht.

\begin{abstract}
Drei Beispiele dieses Dramentyps: Peribánez y el Comendador de Ocaña (1610?), Fuenteovejuna (ca. 1613), El mejor alcalde, el Rey (ca. 1621) weisen folgende strukturellen Gemeinsamkeiten auf: Beginn mit Hochzeit eines bäuerlichen Paares, der Bräutigam ist ein "villano noble" und bekleidet oft ein Ehrenamt bzw. ist sogar ein kleiner Hidalgo. Der örtliche Feudalherr ist entweder von Natur aus böse oder wird durch eine "pasión" geblendet und stellt so der Frau mit List und Gewalt nach. Angesichts dieser Situation nehmen die beleidigten villanos pflichtwidrig die Rache selbst in die Hand $(1,2)$ oder wenden sich an den König (3); dementsprechend erfolgt zunächst eine Untersuchung bzw. Strafandrohung gegen sie $(1,2)$ oder es wird die Strafe an dem Feudalherrn vollstreckt (3). In jedem Fall erhalten jedoch die villanos am Ende Recht, wie es auch moralisch gerechtfertigt erscheint, und zwar durch eine jeweils souveräne Entscheidung des Königs, die freilich dadurch erleichtert werden kann, $\mathrm{da} B$ die Feudalherren jeweils nicht nur gegen die Moral verstoßen und sich an ihren Untertanen vergehen, sondern auch dem König die Treue brechen. Besonders interessant sind die Frauenfiguren, v.a. Casilda in Peribáñez als die treue Ehefrau par excellence, oder Laurencia in Fuenteovejuna, die nach ihrer Vergewaltigung die zögernden Männer des Dorfes zum Aufstand mitreißt, indem sie ihnen ihre Männlichkeit abspricht, wenn sie zu feig sind, die Frauen zu verteidigen. Eine Fortsetzung findet die Tradition des Ehrendramas in der vorgeführten Konstellation schließlich in Calderóns El alcalde de Zalamea.
\end{abstract}

2) Das lyrische Drama: Manchmal sind Lopes Dramen so stark lyrisiert, daß sie förmlich um ein oder mehrere Gedichte gebaut werden, besonders, wenn sie Romanzenstoffe behandeln: so etwa El caballero de Olmedo, beruhend auf der gleichnamigen Romanze über den Eifersuchtsmord an einem jungen Ritter 1521 zwischen Medina del Campo und Olmedo. Das Stück enthält auch Elemente des Celestina-Stoffes. Vom Personal her liegt ebenfalls eine Gattungsmischung vor (zahlreiche Dienerfiguren), der Ausgang ist der einer Tragödie (Tod des galán, Bestrafung der Mörder durch den König).

3) Tragödie: Die reine Tragödie ist bei Lope selten, ein Beispiel wäre jedoch sein bekanntes Stück El castigo sin venganza (1631), beruhend auf einem in der 44. Novelle Bandellos behandelten historischen Stoff, der unerlaubten Liebe der jungen Frau des "libertinen" Herzogs von Ferrara zu ihrem Stiefsohn, der schließlich vom Herzog gezwungen wird, die Geliebte zu töten, um dann als Muttermörder hingerichtet zu werden. Die Hauptpersonen sind durchweg Hochadelige, und durch die geschickte Schlußwendung (der "böse" Herzog ist plötzlich geläutert, ehe er zu der schrecklichen Rachetat schreitet) ist angesichts der Fatalität der Katastrophe sogar ein Hauch von antiker Schicksalstragödie zu spüren. 
4) comedia de capa y espada: Ursprünglich rein auf Äußerlichkeiten anspielend (nächtliche Straßen- bzw. Fechtszenen), bezeichnet dieser Begriff bald die handlungsbetonte Intrigenkomödie schlechthin, in der mehrere galán-Figuren um eine oder mehrere Damen werben, bis es schließlich ein happy end mit mehrfacher Hochzeit gibt. Eine der bekanntesten und auch heute noch gespielten Komödien dieses Typs ist La dama boba (1613), in der die Charakteristika der capa y espada-Komödie mit einer Behandlung der neoplatonischen Liebestheorie verbunden werden:

Liseo reist mit dem gracioso Turín nach Madrid, wo er sich aufgrund einer Vereinbarung
der Eltern mit der dummen, aber mit einer reichen Mitgift ausgestatteten Finea verheiraten
soll. Er lehnt sie aufgrund ihrer Dummheit bald ab und fühlt sich zu ihrer Schwester Nise
hingezogen, die einen literarischen Salon führt. Nise liebt Laurencio, der aber kein Geld hat
und sich deshalb in einem Monolog-Gedicht davon zu überzeugen versucht, daß er Nise
aufgeben muB, weil ein caballero pobre eine reiche Partie braucht. Er wendet sich deshalb
Finea zu und erweckt in ihr tatsächlich Liebe, die sie allmählich (zwischen den Akten ver-
geht jeweils ein Monat) klüger werden läßt. Dazwischen kommt es fast zum Duell zwischen
Laurencio und Liseo, wobei ersterer glaubt, um Finea, letzterer, um Nise zu kämpfen. Als
Finea im letzten Akt durch Liebe klug geworden ist, will Liseo nun doch um sie werben, sie
ist aber nun sogar klug genug, sich wieder dumm zu stellen. Am Schluß versteckt Finea sich
mit ihrer Zofe auf Befehl des Vaters in derselben Rumpelkammer, in der sie vorher Lau-
rencio und seinen Diener (gracioso) verborgen hat. Als die vier gefunden werden, bleibt aus
Ehrengründen nur die Hochzeit übrig, es gibt also eine doppelte Doppelhochzeit (zwei
Herrenpaare, zwei Dienerpaare).

5) comedias historicas: Hier behandelt Lope Stoffe aus der spanischen Geschichte, teilweise auch aus mittelalterlichen Epen und Romanzen. Die Einheiten von Zeit und Ort werden bei diesem Typus gar nicht mehr respektiert (so vergehen etwa in Los paces de los Reyes o judía de Toledo zwischen den Akten einige Jahrzehnte).

Weitere Dramentypen sind etwa die italienisch beeinflußten Schäferdramen (comedias pastoriles), die auch parodistischen Charakter tragen können (Arcadia) oder der weite Bereich des religiösen Theaters (autos sacramentales, comedias de santos). Insgesamt soll Lope nach eigener Aussage an die 2000 Stücke geschrieben haben, ca. 450 davon sind uns erhalten.

\subsection{Tirso de Molina (ca.1580-1648)}

Tirso de Molina ist das Pseudonym des Mercedariermönchs Gabriel Téllez. Er wird 1606 zum Priester geweiht, im selben Jahr beginnt seine Aktivität als Theaterautor. 1625 wird er von der "Junta de reformación" wegen seiner "profanen" comedias verurteilt und aus Madrid fortgeschickt. In Sevilla schreibt er dann El condenado por desconfiado und El burlador de Sevilla. Im Zentrum seiner Stücke steht meist eine moralistische Sittenkritik aus christlicher Perspektive, ${ }^{33}$ daneben ist Tirso aber auch der Autor von perfekt gebauten Unterhaltungsstücken vom Typus der comedia de capa y espada (z.B. "Don Gil de las calzas verdes").

\footnotetext{
${ }^{33}$ Dietrich Briesemeister spricht sogar von einer "eindrucksvollen Predigt von der Bühne herab" [in: Klaus Pörtl (Hg.), Das spanische Theater..., S. 229].
} 


\begin{abstract}
Sein bekanntestes Stück ist El burlador de Sevilla o convidado de piedra, mit dem der Siegeszug des Don Juan-Stoffes beginnt. Es geht vermutlich auf volkstümliche Quellen zurück, wenigstens was das Motiv des steinernen Gastes anbelangt. Der erste Teil des Dramas ist streng symmetrisch gebaut: Don Juan verführt zwei adelige Damen und zwei Frauen aus dem Volk, immer alternierend, und zwar mehr durch Gewalt und List als durch Liebeskünste. Sein Diener/gracioso Catalinón warnt ihn mehrmals vor Gottes Strafe, er antwortet stets mit einem leitmotivischen "Tan largo me lo fiáis" (So lange gebt ihr mir Kredit!). Erst nach der letzten Verführung tritt das zweite Motiv auf, die Rache des Toten (steinerner Gast), die mit Tod und Höllenfahrt des Don Juan endet, wobei seine Bitte um einen Priester "zu spät" kommt. Don Juan ist zum Unterschied zu späteren Bearbeitungen (z.B. Molière) kein Libertin, Freigeist und Vernunftmensch, sondern dem Wertekatalog seiner Zeit durchaus verhaftet (Kult der Ehre und Tapferkeit, der allerdings Listen und brutale Gewalt zuläßt) und ein exemplarischer Sünder: er glaubt an Gott, denkt sich aber das Jüngste Gericht so fern, daß er sich einstweilen darum nicht zu kümmern braucht.
\end{abstract}

Ein ähnliches, noch eindeutiger religiöses Drama über Sünde und Verdammnis bildet $E l$ condenado por desconfiado. Hier spielt der theologische Gnadenstreit zwischen den Jesuiten (Molinisten) und den Dominikanern um 1600 herein, in dem es um die Frage des freien Willens geht, die auch noch in Pedro Calderóns La vida es sueño erörtert wird. Typisch für Tirso de Molina sind darüber hinaus die besonders aktiven Frauengestalten, mit deren Gestaltung als eigentliche Protagonistinnen seiner Dramen er über die rein äußerliche und wohl auch ein wenig voyeuristisch motivierte Vorliebe des Siglo de Oro für Frauenrollen in Männerkleidern weit hinausgeht: vgl. v.a. die Titelfigur in Marta la piadosa und die Juana in Don Gil de las calzas verdes.

\title{
9.4. Juan Ruiz de Alarcón y Mendoza (ca.1580-1639)
}

Juan Ruiz de Alarcón stammt aus Mexiko, war aber Jurist in Madrid und hat in dieser Zeit für das spanische Publikum seine Stücke geschrieben. ${ }^{34} \mathrm{Er}$ ist klein, rothaarig, bucklig und wird von vielen Autoren seiner Zeit verspottet (Góngora nennt ihn etwa "bucklige Schildkröte", Suárez de Figueroa "Affe in Menschengestalt"), was seine literarische Außenseiterrolle unterstreicht. In seinen Stücken setzt er sich über viele sittliche Normen hinweg, versteht sich wie Tirso de Molina als Moralist, aber im französischen Sinne, d.h. als eine Art humanistischer, bisweilen geradezu voraufklärerischer Sittenkritiker ohne den religiösen Hintergrund Tirso de Molinas. Eines der Hauptziele seiner Kritik ist der gesellschaftliche Zwang zu Verstellung, Heuchelei und Rollenspiel. In der Behandlung seiner sittenkritischen Themen zeigt er erste Ansätze zur Typen- bzw. Charakterkomödie, wie sie später bei Moreto und in Frankreich bei Molière ausgebildet wird. Sein (neuartiger) Ehrbegriff setzt sich zusammen aus Vernunft, durch edle Taten erworbenem Adel der Person, aus der Beherrschung der Leidenschaften und aus dem Widerstand gegen Vorurteile. Die von ihm angeprangerten negativen

\footnotetext{
${ }^{34}$ Deshalb seine Behandlung in dieser spanischen Literaturgeschichte. Der Streit über "mexicanidad" oder "hispanidad" von Alarcón beschäftigte die Kritik vor allem in der ersten Hälfte unseres Jahrhunderts (siehe dazu Antonio Alatorre, "Brief History of a Problem: The Mexicanidad of Ruiz de Alarcónn, in: Anthology MCC 1956, Mexico City College, México 1956), ist aber heute wohl endgültig zugunsten seiner "hispanidad" entschieden.
} 
Eigenschaften sind z.B. die Lüge in La verdad sospechosa, der böse Tratsch in Los paredes oyen (statt dem schönen Verleumder Mendo wird Juan, "pobre y feo", aber moralisch integer, als Gatte gewählt), oder die Undankbarkeit in $L a$ prueba de las promesas. Sein Verhältnis zum Publikum, das er in der Vorrede zum ersten Band seiner Dramen (1628) als "vulgo" und "bestia" bezeichnet, ist stets gespannt; Höhepunkt ist die Skandalpremière seines einzigen religiösen Stücks El Anticristo (1623), die durch ein Stinkbombenattentat gesprengt wird.

\section{Die Generation Calderóns}

\subsection{Pedro Calderon de la Barca (1600-1681)}

Calderón ist seit der Romantik der im deutschen Sprachraum am stärksten rezipierte Autor des Siglo de Oro und auch das liebste Studienobjekt der deutschen Hispanistik. Hat man bisher an seinem Werk vor allem Dramaturgie und Ideengeschichte der bekannteren Stücke in den Mittelpunkt gestellt, so legen neuere Ansätze stärkeres Gewicht einerseits auf den "unbekannten" Calderón (etwa der entremeses oder der fiestas), ${ }^{35}$ andererseits auf das soziale und ökonomische Umfeld seines Schaffens, ${ }^{36}$ das in eine Zeit fällt, in der der wirtschaftliche und politische Niedergang immer deutlicher spürbar wird: Das Gold aus Amerika verursacht eine starke Inflation, die dadurch verarmten kleinen Adeligen und Bürger versuchen, sich ein Hofamt als Versorgungsgarantie zu besorgen. Auch das Theater konzentriert sich mehr und mehr am Hof, das Palasttheater beginnt das Corral-Theater abzulösen. Calderóns Familie hat ein solches Hofamt inne; nach dem frühen Tod des Vaters beginnt Pedro jedoch aus wirtschaftlicher Not im Stil der comedia nueva für das Theater zu schreiben. In den 20er Jahren entstehen vor allem comedias de capa y espada (Höhepunkt 1629 mit La dama duende und Casa con dos puertas mala es de guardar), aber auch erste religiöse Stücke (v.a. comedias de santo: La devocion de la cruz 1625, El príncipe constante 1629). Schon in dieser Zeit läßt sich aus technischen Details erschließen, daß Calderón nicht nur für das Corral-Theater arbeitete, sondern das (überdachte und künstlich beleuchtete) Palasttheater vor Augen hatte. ${ }^{37}$ In den 30er Jahren verlegt er sich mehr und mehr aufs Palasttheater und festigt seine Stellung bei Hof: 1635 wird er Hofdichter, 1637 Santiago-Ritter, von da an beinahe jedes Jahr Autor des Fronleichnamsspiels von Madrid. Dazu inszeniert Calderón barocke Bühnenfeste mit dem italienischen Architekten Cosme Lotti (z.B. 1635 El mayor encanto, amor zur Eröffnung des neuen Retiro-Palastes). 1636 erscheint die Pri-

\footnotetext{
${ }^{35}$ Vgl. etwa Sebastian Neumeister, Mythos und Repräsentation. Die mythologischen Festspiele Calderóns, München 1978 und die neueren Texteditionen von Calderóns entremeses sowie den Aufsatz von Hugo Laitenberger, "Ehre und Ehrenrache in den Zwischenspielen von Calderón", in: Angel San Miguel (Hg.), Calderón..., S. 95-113.

${ }^{36}$ So vor allem Manfred Engelbert, "Calderón de la Barca", in: Klaus Pörtl (Hg.), Das spanische Theater..., S. 240-279.

${ }^{37}$ Das zeigt sich an der Bedeutung des Lichtes in den "Kobold"-Szenen, insbesondere im 2. Akt, die wohl nur bei der Möglichkeit einer angemessenen Verdunkelung wirksam werden konnten.
} 
mera Parte de las comedias im Druck. In diesem Jahrzehnt entstehen auch seine bedeutendsten Werke (La vida es sueño, El alcalde de Zalamea, El gran teatro del mundo), danach tritt eine Schaffenspause ein: 1640-42 kämpft er im Krieg gegen das aufständische Katalonien, 1644-49 sind die Theater wegen mehrerer Todesfälle in der königlichen Familie geschlossen. Calderón muß daher 1646 in den Dienst des Herzogs von Alba treten. Ähnlich wie Lope de Vega hat er mit 50 Jahren eine spirituelle Krise, wird in der Folge 1651 zum Priester geweiht und schreibt danach nur noch religiöses Theater und fiestas mitológicas bzw. zarzuelas (musikalische Gelegenheitsstücke, die ab 1656 im Lustschlößchen Zarzuela aufgeführt werden) bzw. arbeitet viele frühere Werke "a lo divino" um.

Seine Dramenkonzeption bringt eine gewisse Straffung gegenüber Lope de Vegas "comedia nueva" mit sich: es gibt nun meist eine Haupt- und eine Nebenhandlung, die beide dasselbe Thema behandeln (z.B. in La vida es sueño der Vater-Kind-Konflikt Basilio/Segismundo bzw. Clotaldo/Rosaura), sowie eine stärkere Ausarbeitung der Charaktere gegenüber Lopes vorwiegend handlungsbetonter comedia.

Vor allem aber fällt in die Zeit Calderóns der Höhepunkt des auch schon in der Lope-Zeit gepflegten Fronleichnamsspiels auto sacramental: ein aus "lebenden Bildern" in der Prozession entstandenes einaktiges lyrisch-dramatisches Spiel, das stark mit allegorischen Figuren arbeitet. Es wird auf mehreren Wagen in den Straßen der Städte aufgeführt. Das Thema ist dem Anlaß entsprechend die Eucharistie, aber da das Fest erst im Mittelalter von der Kirche eingeführt wurde und auf keine biblische Geschichte verweist, ist der Autor in der Gestaltung der Handlung relativ frei. Die Struktur umfaßt im Idealfall symbolisch drei Phasen: Schöpfung, Sündenfall, Erlösung. Das einheitstiftende Prinzip ist die Entfaltung einer zusammenhängenden Bildebene, wie jener des Marktes in $\mathrm{El}$ gran mercado del mundo oder der des Theaters als Sinnbild der Welt in El gran teatro del mundo.

El gran teatro del mundo (vor 1635): Gott $=$ autor, Welt $=$ Bühne, Menschen $=$ Schauspieler, die mit den ihnen vom autor zugeteilten Rollen nicht alle zufrieden sind, insbesondere der Bauer, eine Art gracioso, der lieber eine mit weniger Arbeit verbundene Rolle hätte. Am Ende des Spiels müssen sie alle ihre Kostüme wieder abgeben, und es erfolgt eine Kritik der Darstellung, (d.h. eine Beurteilung dessen, was jeder aus seiner Rolle gemacht hat). Als Ergebnis derselben kommt der Reiche in die Hölle, der König, die Schönheit und der Bauer ins Fegefeuer, der Arme und die discreción (die eine Nonne und damit den geistlichen Stand im allgemeinen darstellt) gleich in den Himmel. Der Souffleur dazu heißt "Gesetz der Gnade" und souffliert ständig den "Refrain": "Obrar bien, que Dios es Dios."

Die Darstellung der Welt als Theater ist eine der Hauptmetaphern des Barock. Sie findet sich schon bei Lope in seinem Märtyrerdrama Lo fingido verdadero über einen Schauspieler, der zur Zeit der Christenverfolgungen einen Christen spielt und plötzlich auf offener Bühne seine Rolle zu leben beginnt, d.h. bekehrt wird, im weiteren Sinn auch in Cervantes' Pedro de Urdemalas und Ruiz de Alarcóns La prueba de las promesas. 
Auch die übrigen religiösen Genres (comedias de santo - Märtyrer- und Heiligenstücke) pflegt Calderón von Beginn an: etwa in El mágico prodigioso, das die Bekehrung eines Zauberers Cipriano in frühchristlicher Zeit zum Inhalt hat und das Motiv des Teufelspaktes enthält.

Besonders klar tritt in Calderons Werk auch die barocke desengaño-Thematik zutage, d.h. die Aufhebung der Täuschung des Menschen durch die diesseitige Welt, die ihm Realität vorgaukelt. Dies verdeutlicht er insbesondere in der Thematik von Leben und Traum in seinem berühmten Drama La vida es sueño:

\begin{abstract}
Der polnische König Basilio hat seinen Sohn Segismundo wegen einer bösen astrologischen Voraussage in einen Turm gesperrt, wo ihm der Wächter Clotaldo seine Identität verheimlichen muß. Die von einem polnischen Adeligen verführte und verlassene Rosaura kommt in Männerkleidern mit ihrem Diener, dem gracioso Clarín, zu diesem Turm, soll getötet werden, weil sie das Geheimnis entdeckt hat, zeigt aber einen Degen vor, an dem Clotaldo erkennt, daß sie sein Kind ist. Nun kann er das Urteil nicht vollstrecken. Unterdessen entdeckt Basilio sein Geheimnis seinen Vertrauten; er hat als Probe den betäubten Segismundo in den Palast bringen lassen, wo er für einen Tag König sein darf. Der Prinz ist jedoch zornig und aufbrausend, versucht, Frauen zu vergewaltigen und wirft einen Diener aus dem Fenster. Da läßt inn der Vater wieder schlafend zurückbringen, so da $\beta$ er glauben muß, es sei alles ein Traum gewesen. Im 3. Akt kommt es jedoch zum Volksaufstand, Segismundo wird fast gegen seinen Willen aus dem Turm geholt, siegt und verzichtet zugleich: auf Rache gegen den Vater, auf Rosaura, die er liebt, die aber ihren Verführer Astolfo heiraten will; ja, er bestraft sogar die Führer seines eigenen Aufruhrs. Das Motto des Stücks wird schon am Ende des 2. Aktes ausgesprochen: "¿Qué es la vida? Un frenesí./ ¿Qué es la vida? Una ilusión,/ una sombra, una ficción;/ y el mayor bien es pequeño;/ que toda la vida es sueño, / y los sueños, sueños son." Das Stück zeichnet sich neben den pschologischen Studien der Hauptpersonen und der originellen Gestaltung des gracioso zu einer beinahe tragischen Figur, die am Schluß eben deshalb, weil sie sich aus Feigheit versteckt, in den Tod läuft, auch im Bereich des Lyrischen durch einige Höhepunkte aus (wie etwa die berühmten Klage-décimas des Segismundo aus dem 1. Akt).
\end{abstract}

Den Höhepunkt des Ehrendramas in der Lope-Tradition, d.h. in Verbindung mit der Figur des villano noble, bildet Calderóns El alcalde de Zalamea (1635):

Pedro Crespo, ein reicher, ehrlicher Bauer mit Tochter Isabel und Sohn Juan, lehnt es ab, sich einen Adelsbrief zu erkaufen, und muß daher durchziehende Soldaten auch bei sich einquartieren. Deren Hauptmann interessiert sich für Isabel, die der Vater in einer Dachkammer versteckt hat, und inszeniert eine Verfolgungsjagd mit seinen eigenen Leuten, um so in das Versteck einzudringen. In die darauf folgende Auseinandersetzung platzt der $\mathrm{Ge}$ neral Don Lope, der sich selbst einquartiert und dem Hauptmann ein anderes Haus anweist. D. Lope und Pedro Crespo, zwei knorrige Alte, streiten, gewinnen einander aber sofort lieb. Als die Soldaten weiterziehen, gibt Crespo D. Lope seinen Sohn Juan als Rekruten mit. Aber der Hauptmann kehrt in der Nacht zurück, raubt Isabel, vergewaltigt sie und überläßt sie im Wald ihrem Schicksal. Pedro Crespo wird an einen Baum gebunden. Als Isabel ihn findet und ihm alles erzählt, berichtet ein Bote, da $B$ Crespo soeben zum Alkalden gewählt worden ist. Als solcher bestraft er seinen Sohn, der auf die Nachricht vom Raub seiner Schwester hin fahnenflüchtig geworden ist und läßt den Hauptmann, der nur wenige Soldaten bei sich hat, einsperren. Der Hauptmann weist ihn darauf hin, da $\beta$ er als Bauer kein Urteil über Adelige fällen darf, Crespo kniet vor ihm nieder und bietet ihm all sein Hab und Gut an, wenn er seine Tochter heiratet, um die Schande wiedergutzumachen. Als der Hauptmann sich dennoch weigert, läßt Crespo ihn hinrichten. Da kommt D. Lope zurück und belagert das Dorf, um den Hauptmann herauszuholen. In dieser bedrohlichen Lage erscheint plötzlich als deus ex machina der König, entscheidet für Crespo und macht ihn zum Alkalden auf Lebenszeit. Das Grund-Schema ist dasselbe wie bei Lope de Vega, 
aber die Figuren sind psychologisch noch mehr ausgearbeitet, auch die Nebenfiguren (etwa die pikaresken Soldatentypen).

Insgesamt ist Calderón wohl als Moralist christlicher Prägung zu verstehen, selbst die graciosos werden bei ihm mehr und mehr zu Trägern moralischer Wahrheit, sei es auch nur durch gutes oder schlechtes Beispiel - so Clarín in $L a$ vida es sueño. Dennoch sind die meisten moralischen Begriffe nicht mehr eindeutig: insbesondere kann die Ehre einerseits für die von Gott gegebene Würde des Menschen in seinem Stand stehen (El alcalde de Zalamea), andererseits aber auch für eine Art menschlichen Wahns, wenn sie durch Übererfüllung absurde Züge annimmt wie in El médico de su honra, $A$ secreto agravio, secreta venganza oder El pintor de su deshonra.

\subsection{Autoren um und nach Calderón}

Francisco de Rojas Zorrilla (1607-48): Seine wesentlichste Schaffensperiode sind ebenfalls die 30er Jahre. Er liebt "außerordentliche" Charaktere und schreckliche Taten, wie sie auch für das französische Barocktheater (Hardy) typisch sind (vgl. El Caín de Cataluña, Morir pensando matar, und andere Stücke über Brudermord, Gattenmord, Vergewaltigung). Ab 1638 beginnt er sich den charakterzentrierten comedias de figurón zuzuwenden. Von ihm stammt auch die erste Komödie, in der Herr und Diener die Rollen tauschen: Donde hay agravios no hay celos mit dem gracioso Sancho als komisch-parodistische Herrenfigur. Diese Konstellation wurde später, vor allem in Frankreich, mehrfach nachgeahmt, bis hin zu Marivaux' Le jeu de l'amour et du hasard..$^{38}$

Agustín de Moreto y Cabaña (1618-1669): Sein Schaffen konzentriert sich in den 50er Jahren und bringt den Höhepunkt der comedia de figurón, die um einen satirisch betrachteten, meist auf eine hyperbolisch beschriebene Eigenschaft beschränkten Charakter zentriert ist. Dadurch tritt in diesem Charakter eine Verbindung der Rollenfunktionen von galán (Herr und Hauptheld) und gracioso (komische Figur) ein; der eigentliche gracioso wird infolgedessen noch stärker zur schlauen, ja überlegenen Figur. Die bekanntesten figurones sind der Schönling in El lindo don Diego und die eitle Cecilia in De fuera vendrá. Dazu schrieb Moreto galante Palastkomödien (z.B. El desdén con el desdén) und historische Dramen.

Francisco Antonio de Bances y López Candamo (1662-1704) war während der 80er und 90er Jahre Hofdichter und schrieb nur mehr für das Palasttheater, v.a. über Stoffe aus der ausländischen Geschichte (El esclavo en grillos de oro über Kaiser Trajan, Quién es quien premia el amor über Christina von Schweden, ihre Konvertierung und Abdankung), die er geschickt zu verdeckten aktuell-politischen Ratschlägen gestaltet. ${ }^{39}$ Seine Schrift Teatro de los Teatros stellt gleich-

\footnotetext{
${ }^{38}$ Die Komödie gelangte über Paul Scarrons französische Nachdichtung Jodelet ou le maître valet (1643) nach Frankreich.

${ }^{39}$ So soll mit beiden zitierten Stücken dem impotenten, kinderlosen Carlos II. die Bestimmung eines Nachfolgers in der Art der römischen Adoptivkaiser (esclavo) bzw. eine Abdankung zur Regelung
} 
zeitig eine Geschichte des Theaters im Siglo de Oro und den letzten großen theoretischen Traktat dieser Zeit dar.

Mit Bances Candamo geht die unmittelbare Tradition des spanischen Theaters zu Ende. Das Corral-Theater war schon vor ihm allmählich verkümmert und stark repetitiv geworden. Die Theaterverbote häuften sich, und mit dem Spanischen Erbfolgekrieg fiel auch der Hof als Impulsgeber und Spielort aus. Die Theaterdichtung des 18. Jahrhunderts versucht unter französischem Einfluß einen neoklassischen Neubeginn mit strenger Trennung der Gattungen, Einhaltung der klassischen Regeln und dergleichen mehr. Manche Züge des Siglo-deOro-Theaters bleiben aber im volkstümlichen Musiktheater der Zarzuela und dem "género chico" des "sainete" erhalten.

\section{Bibliographie}

Alborg, J.L., Historia de la literatura española, Bd. II, Madrid 1970

Arroniz, Othón, Teatros y escenarios del siglo de oro, Madrid 1977

Asensio, Eugenio, Itinerario del entremés. Desde Lope de Rueda a Quiñones de Benavente, Madrid 1971

Aubrun, Charles V., La comédie espagnole (1600-1680), Paris 1966 (span. Ausgabe Madrid ${ }^{2} 1981$ )

Canavaggio, Jean, Cervantès dramaturge. Un théatre d naître, Paris 1977

Criado de Val, Manuel (Hg.), Lope de Vega y los orígenes del teatro español (actas del primer congreso internacional sobre Lope de Vega), Madrid 1981

Diez Borque, José María, u.a. (Hg.), Historia del teatro en España, Bd.1: Edad Media, Siglos XVI y XVII, Madrid 1984

-, Sociología de la comedia española del siglo XVI, Madrid 1976

Flasche, Hans (Hg.) Calderón de la Barca, Darmstadt 1971 (Wege der Forschung Bd. CLVIII)

Fries, Fritz Rudolf, Lope de Vega, Frankfurt/M. 1979

Froldi, R, Lope de Vega y la formación de la comedia, Salamanca 1968

Hermenegildo, Alfredo, La tragedia en el renacimiento español, Barcelona 1973

Hesse, Everett W., La comedia y sus intérpretes, Madrid 1972

Heydenreich, Titus (Hg.), Pedro Calderón de la Barca (1600-1681). Beiträge zu Werk und Wirkung, Erlangen 1982

Kinter, Barbara, Die Figur des Gracioso im spanischen Theater des 17. Jahrhunderts, München 1978

Müller-Bochat, Eberhard (Hg.), Lope de Vega, Darmstadt 1975 (Wege der Forschung Bd.CCLIV)

Oehrlein, Josef, Der Schauspieler im spanischen Theater des Siglo de Oro 1600-1681. Untersuchungen $z u$ Berufsbild und Rolle in der Gesellschaft, Frankfurt 1986

Pörtl, Klaus (Hg.), Das spanische Theater. Von den Anfängen bis zum Ausgang des 19. Jahrhunderts, Darmstadt 1985

Ramos Ortega, Francisco (Hg.), Teoría y realidad en el teatro español del siglo XVII. La influencia italiana (Actas del Coloquio de Roma 1978), Roma 1981

Reichenberger, K.u.R., Das spanische Drama im Goldenen Zeitalter. Ein bibliographisches Handbuch, Kassel 1989

der Nachfolge nahegelegt werden. Der esclavo enthält darüber hinaus erzieherische Passagen in der Art eines Fürstenspiegels - siehe dazu Carmen Díaz Castañon, " $\mathrm{El}$ esclavo en grillos de oro. Acercamiento al teatro político de Bances Candamo", in: Francisco Ramos Ortega (Hg.), Teoría y realidad..., S. 387-418. 
Roloff, Volker, Harald Wentzlaff-Eggebert (Hg.), Das spanische Theater, Düsseldorf 1988

Ruiz Ramón, Francisco, Historia del teatro español, I (Desde sus origenes hasta 1900), Madrid 1967, ${ }^{2} 1971,{ }^{3} 1979$

Salomon, Noël, Recherches sur le thème paysan dans la "Comedia" au temps de Lope de Vega, Bordeaux 1965

San Miguel, Angel (Hg.), Calderón. Fremdheit und Nähe eines spanischen Barockdramatikers, Frankfurt 1988

Sánchez Escribano, Federico, Alberto Porqueras Mayo (Hg.), Preceptiva dramática española. Del renacimiento al barroco, Madrid ${ }^{2} 1972$

Sánchez Romeralo, Antonio, Lope de Vega: El teatro, Madrid 1989, (2 Bde.)

Shergold, Norman D., A History of the Spanish Stage from Medieval Times until the End of the Seventeenth Century, Oxford 1967

Teyssier, Paul, Gil Vicente - o autor e a obra, Lissabon 1982

Wilson, E.M., D. Moir, The Golden Age Drama 1492-1700, London/N.York 1971

Ziomek, Henryk, A History of Spanish Golden Age Drama, Kentucky University Press, 1984 


\section{Index}

(Angegeben werden die besprochenen und erwähnten Schriftsteller.)

Abarca de Bolea Aranda, Pedro Pablo, conde de 234

Abbat, Per 7

Acuña, Rosario de 312

Aesop 262

Aguado, Alejandro 234

Agustí, Ignacio 338

Alarcón y Ariza, Pedro Antonio de 306, 307

Alarcón y Mendoza, Juan Ruiz de 170, 185, 187

Alarcón, Fray Juan de 32

Alarcón, Luis de 90, 214

Alas y Ureña, Leopoldo ('Clarín') 189, 285, 303, 308, 309, 311

Alberti, Rafael $343,345,348,351-353,368$, $377,378,380,381-383,385,390$

Alcázar, Baltasar del 142

Aldana, Francisco de 141

Aldecoa, Ignacio 335

Aleixandre, Vicente $343,348,352-355,362$

Alemán, Mateo 103, 110, 111

Alfieri, Vittorio 288

Alfonsi, Petrus: eigtl. Rabbi Moises Sefardi $3,4,30$

Alfonso $X$ el Sabio 9, 12, 17-21, 30, 31, 161

Almeida, Juan de 133

Alonso de Madrid, Fray 207

Alonso de Santos, José Luis 391

Alonso, Dámaso 153, 343, 348, 355, 357

Alonso, José Luis 391

Altamira, Rafael 304

Altolaguirre, Manuel 348,381

Alvarez de Cienfuegos, Nicasio 264

Alvarez de Cueto, Leopoldo, Marqués de Valmar 302

Alvarez de Toledo, Gabriel 258

Alvarez de Villasandino, Alfonso 25, 51

Alvarez Quintero, Joaquín 370
Alvarez Quintero, Serafin 370

Alvarez, J.A. 364

Alvarez, Miguel de los Santos 291

Amat y Maestre, Miguel 293

Andrés, Juan 243

Apuleius 106, 109

Arcipreste de Hita, eigtl. Juan Ruiz 57, 163

Arconada, César 330, 331

Arcos, Gómez 387

Arderius, Joaquín 330

Arenal, Concepción 304

Argensola, B. Leonardo de 135, 146, 147

Arguijo, Juan de 142, 146

Aribau, B. Carlos 302

Ariost 106

Ariosto, Ludovico 125, 145

Aristoteles 3, 32, 177, 178, 197, 223, 387

Arnaut Daniel 120

Arniches y Barrera, Carlos 329, 370, 389

Arolas, Juan 291

Arrabal, Fernando 383

Arriaza y Superviela, J.B. 265

Arróniz, Teresa 312

Artaud, Antonin 384, 388

Aub, Max 332, 378, 380-383

Augustinus 29, 202, 208

Ausonius 53, 129

Avecilla, Pedro Alonso de 293

Averçб, Luis de 40

Averroes 3

Avicenna 3

Ayala, Francisco 332

Ayguals de Izco, Wenceslao 293

Aza, Vital 301

Azcárate, Gumersindo 303

Azorín, eigtl. José Martínez Ruiz 308, 319, $324,326,368,369,372,374,375$

Äsop 106, 223

Bacon, Francis 241, 254

Baena, Juan Alfonso de 25, 42, 43, 49, 50, 52,119

Bakunin, Michail Aleksandrowitsch 304

Balma, Hugues de 201 
Balmes, Jaime 302

Balthasar, Hans Urs von 212

Balzac, Honoré de 312, 315, 325

Bances Candamo, Francisco Antonio de 189, 190, 268, 269

Bandello, Matteo 172

Barclay, John 106

Barea, Arturo 332

Baroja, Pío 317, 324-326, 333

Barral, Carlos 361

Barrès, Maurice 307

Barrientos, Lope de 68

Barrios, Miguel de 199

Baudelaire, Charles 315

Bayle, Pierre 237

Beaumarchais, Pierre-Augustin Caron de 278

Beccaria, Cesare 245, 263

Bellido, José María 389

Bembo, Pietro 120, 123, 127

Benavente, Jacinto $300,368,371,372,374$, 381

Benavente, Luis Quiñones de 182

Benavides, Manuel 330

Benet, Juan 339

Benoît de Sainte-Maure 22

Benvenuto da Imola 53

Berceo, Gonzalo de 13-17

Bergamín, José 348

Bermúdez, Jerónimo 173

Bernhard von Clairvaux 29, 201

Bécquer, Gustavo Adolfo 295-297

Björnson, Björnsterne Martinius 317

Blanco-White, José María 250, 264, 265

Blasco Ibañez, Vicente 312

Bocángel, Gabriel 147

Boccaccio, Giovanni $32,42,71,100,109$, 172

Boccalini, Trajano 106

Boethius 32, 45, 63

Boiardo, Matteo Maria 163

Boileau-Despréaux, Nicolas 265, 269

Bonaventura, eigtl. Johannes Fidanza 29, 201
Boscán, Juan 120, 122-127, 211, 221

Boscà Almugàver, Joan: s. Juan Boscán 124

Böhl de Faber, Cecilia 305

Böhl von Faber, Nicolas 287, 305

Brecht, Berthold 335, 382, 384, 385, 387

Bremond, Henri 212

Breton, André 359

Bretón de los Herreros, Manuel 299

Buero Vallejo, Antonio 368, 374, 377, 383387,390

Burgos, Javier de 301

Burleighs, Walter 30

Butor, Michel 335

Cabal, Fermín 391

Caballero, Fernán, s. Cecilia Böhl de Faber 305, 306

Cabanyes, Manuel de 265

Cadalso, José de 233, 248, 259, 260, 264, 272,288

Calderón de la Barca, Pedro 147, 148, 182, $183,185-189,226,227,232,238,243,266-$ $268,270,271,273,290,310,311,319$

Calderón, A. 146

Calvo Sotelo, Joaquín 381

Campillo, José del 247

Campoamor y Campoosorio, Ramón de 300

Campomanes, Conde de 247

Camprodón, Francisco 300

Camus, Albert 334

Cano y Masas, Leopoldo 302

Cano, Melchor 90, 197, 202, 206

Cañizares, José de 268, 269

Cañuelo, Luis 245, 246

Carb6, Juan Francisco 291

Carlos de Viana 33

Carnero, Guillermo 363, 366, 367

Carranque de Ríos, Andrés 330

Carranza, Bartolomé 206

Carrillo de Albornoz 68

Carrillo y Sotomayor, Luis 150,151

Cartagena, Alonso de 31, 32, 39, 44, 68

Carvajal, Antonio 366 
Carvallo, Luis Alfonso de 176, 178

Casanova, Sofía 312

Casona, Alejandro 368, 369, 378-381, 383

Castellet, J.M. 336, 363, 364, 366

Castiglione, Baldassare 99, 120, 125, 221

Castillejo, Cristóbal de 124

Castillo, Diego Enríquez del 68

Castillo-Puche, José Luis 338

Castro, Guillén de 181

Castro, Rosalía de 291

Catull 126

Cauliaco, Guido de 32

Cavalca, Domenico 29

Cela, Camilo José $334,335,339,340$

Celaya, Gabriel (eigtl. Rafael Múgica) 356, 357,363

Cerdá y Rico, Francisco 242

Cernuda, Luis $348,349,352,353,362$

Cervantes de Salazar, Francisco 90, 216, 218, 220

Cervantes Saavedra, Miguel de 91, 93, 96, $97,101,104,105,136,148,172-175,182$, $187,251,252,294,301,310,324$

Cetina, Gutierre de 120, 121, 122

Céspedes y Meneses, Gonzalo de 108

Chateaubriand, François René Vicomte de 286, 287

Châtillon, Gautier de 14

Cheriton, Odo von 30

Chrétien de Troyes 89, 96

Chueca, Federico 301

Cicero 32, 44, 216, 220

Cisneros, Francisco Jiménez de 199, 202

Clarín, s. Leopoldo Alas y Ureña 306, 311

Clavijo y Fajardo, J. 244, 245, 270

Codax, Martin 9

Coinci, Gautier de 20

Colinas, Antonio 366

Coll, Aliocha 341

Colocci, Angelo 9

Coloma, Luis 306

Columna, Aegidius de 32

Columnis, Guido de 22

Conde, Carmen 342
Condillac, Étienne Bonnot de 288

Contreras, Jerónimo de 104

Corneille, Pierre 181

Coronado, Carolina 291

Corral, Pedro del 69

Cortázar, Julio 335

Cortés, Donoso 283, 302

Costa, Joaquín 304, 323

Cota, Rodrigo de 74, 75, 163, 166

Covarrubias, Sebastián de 89

Córdoba, Martín de 31

Crema, Battista de 202

Cremer, V. 356

Cruz, Ramón de la 275, 298, 299

Cueto, L.A. de 256, 257

Cueva, Juan de la 173, 178

Cunqueiro, Alvaro 340

Curtius, Ernst Robert 197

D'Alembert, Jean Le Rond 237

Dante Alighieri $32,51-54,56,58,59,60,119$, 120,300

Dares Phrygius 21

Darío, Rubén 316, 343, 344, 346, 347

David 119

De la Torre, Francisco 133, 143, 146

Delgado, Agustín 364, 365

Delgado, Jacinto María 251

Delibes, Miguel 335, 339

Della Casa, Giovanni 145, 221

Descartes, René 106, 238, 241

Deza, Diego de 215

Dicenta, Joaquín 369

Dickens, Charles 313, 325

Diderot, Denis 237, 247

Diego de Estella 207

Diego de Valera 31-33, 68

Diego, Gerardo $348,349,352$

Dieste, Rafael 381

Diktys von Knossos 22

Diosdado, Ana 391

Díaz de Toledo, Pedro 33, 44

Díaz Fernández, José 330, 331

Díaz, Juan 91 
Díaz-Plaja, Fernando 333

Díez de Games, Gutierre 42, 68

Doergangk, Heinrich 196

Domínguez Bastida, Adolfo: s. Bécquer 295

Donoso Cortés, Juan 302

Dos Passos, John Roderigo 335

Dostojewski, Fjodor 325

Dumas d.J., Alexandre 300

Dumas, Alexandre 293

Durán, Agustín 287

Dürer, Albrecht 204

Eanes do Coton, Afons 12

Echegaray y Eizaguirre, José $301,302,369-$ 371

Eça de Queiroz, José María de 309

Eekhoud, Georges 317

Eguilaz, Luis de 300

Eiximenis, Francesc 32

El Curioso Parlante, s. Ramón Mesonero Romanos 298

El Solitario, s. Serafín Estébanez Calderón 298

Encina, Juan del $\quad 42,48,49,54,56,61,63$, $64,75,119,120,130,163-165,167,168$, 170, 172, 177

Engels, Friedrich 286

Erasmus von Rotterdam 92, 93, 203-205, 217-219

Escosura, Patricio de la 291, 292, 293

Eslava, Antonio de 113

Espina, Concha 331

Espinel, Vicente 112

Espinosa, Pedro de 145, 146

Espronceda y Delgado, José de 290, 291, 297

Estébanez Calderón, Serafín 298, 307

Estúñiga, Lope de 53

Eusebius 44

Falcón, Lidia 342

Falla, Manuel de 350

Fanelli, Giuseppe 304
Faulkner, William Cuthbert 335

Feijoo, Benito Jerónimo 232, 238-242, 246, 250,311

Fermo, Serafino de 202

Fernán-Gómez, Fernando 391

Fernández de Andrada, Andrés 135

Fernández de Avellaneda, Alonso 93, 96

Fernández de Moratín, Leandro 258, 265 , 266, 270, 275-299, 302

Fernández de Moratín, Nicolás 259, 260, 266, 270-272, 276

Fernández de Palencia, Alfonso 68

Fernández de Velasco, Bernardino 291

Fernández Flórez, Wenceslao 332

Fernández Granell, Eugenio 333

Fernández Villegas, Francisco 320

Fernández y González, Manuel 293

Fernández, Lucas 75, 163, 165, 166, 170

Ferrero, Jesús 341

Ferres, Antonio 333

Fénelon, François de Salignac de La Mothe 250

Ficino, Marsilio 142

Figueroa, Francisco de 122,145

Fígaro, s. Mariano José de Larra 298, 317

Flaubert, Gustave 306, 311, 312

Flores, Antonio 306

Flores, Juan 71, 73, 99

Florian, J.P. Claris de 251

Florez, Enrique 243

Foix, J.V. 348

Foligno, Angela da 201

Fontane, Theodor 311

Forner, Juan Pablo 245, 249, 261

Foxá, Agustín de 331

Franck, César 316

Franz von Sales 207

Franziskus von Assisi 201, 207

Freixas, José María de 298

Fuentes, Carlos 335

Furió Ceriol, Fadrique 195

Gala, Antonio 385, 387, 388

Galiano, Alcalá 289 
Gallardo, José 302

Gallego, Juan Nicasio 265

Ganivet, Angel 283, 316-319

Garcia Burgalês, Pero 11

Garcilaso de la Vega $39,61,98,122,124-$ $134,142,144,145,147,149,150,211$, $257,258,265,353,356,358,362$

García Baena, Pablo 359

García de Castrojeriz, Juan 32

García de la Huerta, Vicente 261, 270, 272, 274

García de Quevedo, José Heriberto 306

García de Santa María, Alvar 68

García Gutiérrez, Antonio 294

García Hortelano, Juan 336

García Jiménez de Cisneros 201

García Lorca, Federico 153, 343, 345, 347 $352,354,368,369,375,377-382,384,385$, 388,390

García Matamoros, Alfonso 90

García Márquez, Gabriel 335, 339

García Nieto, José 356

García Serrano, Rafael 331

García Viñó, Manuel 338

García, Gómez 201

Gaspar, Enrique 369

Gassendi, Pierre 238

Gautier, Théophile 286

Gellius, Aulus 217

Gerardo Lobo, Eugenio 258, 259

Gide, André-Paul-Guillaume 340

Gil de Biedma, Jaime 360, 361, 363

Gil Polo, Gaspar 101

Gil y Carrasco, Enrique 290-292

Gil, Ricardo 316

Gimferrer, Pedro 363, 364, 366

Giner de los Ríos, Francisco 304

Gironella, José María 332

Goethe, Johann Wolfgang v. 126, 285, 256, 291

Goldmann, Max 335

Goldsmith, Oliver 248

González y Díaz-Tuñón, Zeferino 304

González, Angel 360
González, Mariano 293

Gordon Byron, George 286, 287, 300

Gordonius, Bernardus 32

Gottfried von Bouillon 21

Goya, Francisco de 383,385

Goytisolo, Juan 338-340

Goytisolo, Luis 339, 340

Gómez Barroso, Pedro 28

Gómez de Avellaneda, Gertrudis 291, 293

Gómez de la Serna, Ramón 329, 347

Gómez, José Luis 391

Góngora y Argote, Luis de 136, 141, 145$153,155,185,221,223,257,259,348$, $349,351,355,356,362,366$

Görres, Joseph von 212

Gracián Dantisco, Lucas 221

Gracián, Baltasar 105-107, 147, 150, 217, 220-224, 238

Gracián, Diego 90

Granada, Fray Luis de $90,194,201,206$, 207, 216

Grande, Félix 367

Grau, Jacinto $368,372,374$

Gregor der Große 29

Grosso, Alfonso 341

Guerrero, María 390

Guevara, Antonio de 90, 102, 205, 206, 220, 221

Guillén de Segovia, Pero 48

Guillén, Jorge $137,348,349,352,357$

Guzmán, Nuño de 43

Hardy, Alexandre 173, 189

Haro, Luis de 124

Hartzenbusch, Juan Eugenio 294

Hebreo, León 93, 99

Heine, Heinrich 285, 291, 295, 296, 297

Heliodor 104-106, 116

Herder, Johann Gottfried von 196

Hernández, Miguel 353, 354, 377, 381

Herrera Petere, José 331

Herrera, Fernando de 257, 265

Herrera, Francisco de 133, 142-145, 147, 149,150 
Hervás y Panduro, L. 249

Hierro, José 355-358

Hoffmann, E.T.A. 297

Homer 104, 106, 126, 223

Horaz 51, 90, 97, 113, 125, 127, 133-135, 144, 146, 177, 214, 265, 269

Hölderlin, Johann Christian Friedrich 355

Huarte de San Juan, Juan 219

Hugo, Victor 286, 289, 292, 295, 297

Huidobro, Vicente 347,348

Huizinga, Johan 35

Humboldt, Wilhelm von 249

Hurtado de Mendoza, Diego 121, 124, 145

Huysmans, Joris-Karl 315

Húmara y Salamanca, Rafael 292

Ibsen, Henrik 315,317

Iglesias, Pablo 304

Ignatius von Loyola 91, 140, 194, 201, 210

Imperial, Francisco 51,53

Iriarte, Tomás de 262, 273

Isidor von Sevilla 2, 3, 119

Isla, José Francisco de 241, 251

Jardiel Poncela, Enrique 378,382

Jarnés, Benjamín 330

Jáuregui, Juan de 146, 147

Jiménez de Cisneros 219

Jiménez, Juan Ramón 315, 316, 343, 346, $347,349,352,353,357$

Johannes de Ketham 32

Johannes vom Kreuz, s. Juan de la Cruz 196, 199, 201, 208, 209, 210, 212

Jovellanos, Gaspar Melchor de 228, 233, 247, 258, 261, 262, 264, 265, 270, 273

Juan de la Cruz, eigtl. Juan de Yepes y

Alvarez 122, 134, 136, 137, 140, 362

Juan de los Angeles 207

Juan, Jorge 247

Juana Inés de la Cruz 147

Junyent, Sebastián 391

Katharina von Siena 201, 205

Kierkegaard, Sören Aabye 319
Kotska Vayo, Estanislao 292

Krause, Karl Christian Friedrich 303, 304

La Fontaine, Jean de 262

Labordeta, Miguel $358,359,367$

Lafargue, Paul 304

Laforet, Carmen 334, 342

Laguna, Andrés 90, 103

Lanfrancus 32

Laredo, Bernardino de 207

Larra y Sánchez de Castro, Mariano José de $246,288,290,292,294,298,299,307$, 317,385

Larrea, Juan 352

Las Casas, Bartolomé de 249

Lautréamont, Comte de (Isidore-Lucien Ducasse) 362

Lázaro Santana 363

Leonardo de Argensola, L. 135, 146, 147

León y Mansilla, José 259

León, María Teresa 381

Lesage, Alain-René 252

Lessing, Gotthold Ephraim 270

Letamendi, A. de 293

Leyva, José 340

Liñán de Riaza 146

Lipsius, Justus 153

Lista, Alberto 265, 290

Livius, Titus 68

Llampillas, Francisco Xavier 243

Llanos, Valentín 292

Llull, Ramón 138, 198

Locke, John 259

Lopes, Fernâo 67

Losada, Luis de 239

López de Ayala, Adelardo 300

López de Ayala, Pedro 17, 30, 54, 67, 68, 90

López de Mendoza, Fray Iñigo (Marqués de Santillana) 40, 46, 54, 119, 120

López de Segura, Juan 204

López de Ubeda, Francisco 112

López Mozo, Jerónimo 389

López Pelegrín, Santos 298

López Pinciano, Alonso 104, 115, 176, 178 
López Salinas, Armando 333

López Soler, Ramón 293

Luca de Tena, Juan Ignacio 381

Lucan 60

Lucas de Hidalgo, Gaspar 113

Lucena, Juan de 32, 33, 70

Ludolf von Sachsen 54, 201

Luis de León, Fray 133, 134, 135, 137, 146, 147, 194, 195, 197, 199, 208, 211, 257, 265

Luján de Sayavedra, Mateo 111

Lukan 243

Lukács, Gyorgy 335

Lukian 106, 218, 222

Lull, Ramón 300

Luther 300

Luzán y Claramunt, Ignacio $233,245,257$, $259,269,270$

Machado de Silva, F. 111

Machado, Antonio 304, 308, 316, 343-347, 352, 376

Machado, Manuel 316, 376

Machiavelli, Niccolò 167, 222

Macías 25

Macías Picavea 323

Macías Picavea, Ricardo 303

Madrid, Francisco de la 163

Madrigal, Alonso de, genannt $\mathrm{El}$ Tostado $28,39,44$

Maeterlinck, Comte 316,317

Maeterlinck, Maurice 375

Maeztu y Whitney, Ramiro de 304, 319, 324

Maimonides, Moses, eigtl. Rabbi Mose ben Maimon 33

Mal Lara, Juan de 112, 133, 218

Maldonado, Juan 166

Malherbe, François de 144

Mallada, Lucas 323

Mallarmé, Stéphane 346

Malón de Chaide, Pedro 195, 210

Mann, Thomas 310

Manrique, Gómez 42, 43, 47, 74, 163

Manrique, Jorge $39,46,47,56,61,63,76$, 124,242
Manuel, Juan 19, 29, 31

Manzoni, Alessandro 287

Mañas, Alfredo 387

Marc Aurel 220

Marcabrú 11

March, Ausias 56, 120, 124

Mariano Nipho, Francisco 244, 270

Marineo, Lucio 124

Marinetti, Filippo Tommaso Emilio 347

Marino, Giambattista 141, 150

Marivaux, Pierre Carlet de Chamblain de 189, 307

Marmontel, Jean-François 254

Marquina, Eduardo 316, 376

Marsé, Juan 338, 341

Marsillach, Adolfo 391

Martín de Lesaca, Juan 239

Martín Gaite, Carmen 335, 342

Martín-Santos, Luis 337, 338

Martínez Ballesteros, Antonio 389

Martínez Colomer, Vicente 255, 256

Martínez de la Rosa Berdejo Gómez y Arroyo, Francisco de Paula 288, 289

Martínez de Toledo, , Alfonso (Arcipreste de Talavera) 29,71

Martínez Ruiz, José (Azorín) 326, 372

Martínez Sierra, Gregorio 316, 373

Martínez Villerga, Juan 293

Martínez, Martín 239, 241

Marx, Karl 286

Masson de Morvilliers 245, 248

Mateo Zapata, Diego 239

Matheu y Aybar, José María 312

Matilla, Luis 389

Matute, Ana María 336, 342

Maury, Juan 291

Mayans y Siscar, Gregorio 242

Mayoral, Marina 342

Medrano, Francisco de 135, 142

Melanchthon, eigtl. Schwarzer, Philipp 218

Meléndez Valdés, Juan 231-233, 258, 259, 261, 263-265

Mena, Juan de $39,45,47,53,56,59,60,61$, $75,123,124,166$ 
Mendoza, Eduardo 341

Menéndez Pelayo, Marcelino 303, 308

Menéndez Pidal, Ramón 7

Meogo, Pero 10

Mesonero Romanos, Ramón 284, 298, 307

Metastasio, Pietro 258

Mexía, Pedro 90, 216, 217, 218

Mey, Sebastián 113

Mérimée, Prosper 286

Michelet, Jules 292

Mihura, Miguel 378, 382, 384

Milá y Fontanals, Manuel 302

Mira de Amescua, Antonio 181

Miralles, Alberto 389

Miranda, Francisco de 287

Miras, Domingo 385, 389

Miró, Gabriel 328

Mistral, Frédéric 301

Mohedano, Pedro 243

Mohedano, Rafael 243

Molière, eigtl. Jean-Baptiste Poquelin 185, 275, 295

Molina, Luis de 203, 210

Molina, Ricardo 359

Molina, Tirso de (eigtl. Gabriel Téllez) 173, 184, 185, 294, 295

Montano, Arias 90

Monteggia, Luis 287

Montemayor, Jorge de 100, 101, 103

Montengón y Paret, Pedro 254, 255, 261

Montero, Rosa 342

Montesino, Fray Ambrosio 54, 201

Montesquieu, Charles-Louis de Secondat 248

Montoro, Antón 55

Montserrat Roig 342

Mor de Fuentes, José 255

Mora, José J. de 287

Morales, Ambrosio de 207, 216

Moreto y Cabaña, Agustín 185, 189, 270

Moses 119

Motte Fouqué, Friedrich Heinrich Karl de La, Baron 287

Mozart, Wolfgang Amadeus 295
Muñiz, Carlos 385, 387

Muñoz Seca, Pedro 369,370

Muñoz Torrero, Diego 246

Narros, Miguel 391

Navarretes, Ramón de 284

Navarro Martín de Azpilcueta 204

Navarro Villoslada, Francisco 293

Nebrija, Antonio de 32, 46-49, 61, 64, 119, 195, 215, 216

Neira de Mosquera, Antonio 298

Neruda, Pablo 352, 354, 356

Newton, Isaac 237, 241, 263

Nieremberg, Juan Eusebio 201, 212

Nietzsche, Friedrich 315,325

Nieva, Francisco 389

Nipho, J.M. 287

Nodier, Charles 297

Nora, Eugenio de 356

Noroña, Conde de 264

Novalis, Friedrich Leopold, Frhr. v. Hardenberg 285

Nunes, Airas 19

Núñez de Arce, Gaspar 300

Núñez de Reinoso, Alonso 104

Núñez de Toledo, Alonso 28

Núñez, Ferrán 33

Núñez, Hernán 61,112

Ochoa, Eugenio de 292, 305

Ochoa, Juan 312

Olavide, Pablo de 230, 234, 245, 270

Olmo, Lauro 387

Olona, Luis 301

Ordóñez Rodríguez de Montalvo, Garci 23, $74,90,91$

Orozco, Alonso de 210

Ortega Munilla, José 312

Ortega y Gasset, José $227,317,318,328$, 373, 379

Ortiz, Alfonso 33

Ortiz, Lourdes 342

Ortí y Lara, Juan Manuel 304

Ory, Carlos E. de 359,367 
Ossian 258

Osuna, Francisco de 205, 207

Otero, Blas de $355,356,357$

Ovid 44, 128, 141, 151

Padilla, Fray Juan de (genannt El Cartujano) 46, 54

Palacio Valdés, Armando 308, 312

Palanco, Francisco 239

Palma, Barnabé de 205

Palmireno, Juan Lorenzo 217, 224

Panckoucke, Charles-Joseph 237

Paravicino, Hortensio 252

Pardo Bazán, Emilia 308-312

Parini, Guiseppe 258

Pascual, Pere 28

Paso, Alfonso 369, 381, 386

Pasqual, Lluís 391

Pastor Díaz 291

Párraga Martel, Francisco 251

Pedrero, Paloma 391

Pedro de Alcalá, Fray 200

Pemán, José María 381

Pereda y Sánchez de Porrúa, José María de 307, 308, 311

Pessoa, Fernando 345

Petrarca, Francesco $32,56,58,76,119-123$, $125,127,128,133$

Petronius 105

Pérez de Ayala, Ramón 316, 329

Pérez de Guzmán, Fernán 44, 69, 74

Pérez de Hita, Ginés 103, 294

Pérez de Oliva, Hernán 218

Pérez Galdós, Benito 307, 309, 311-315, 319, 324, 326, 369

Pérez Zaragoza y Gođínez, Agustín 288

Pérez, Alonso 101

Pérez, Martín 28

Piccolomini, Enea Silvio 71

Picón, Jacinto Octavio 312

Picón, José 301

Pidal, Pedro José 302

Pilar Sinués, María del 306

Pina, Francisco 331
Pina, Mariano 301

Pineda, Juan de 70

Pirandello, Luigi 372

Plato $42,44,51,177$

Plautus 165, 178

Plutarch 94, 106

Poe, Edgar Allen 307

Polo de Medina 147

Ponce de la Fuente, Constantino 204

Ponte, Pero da 12

Ponz, Antonio 243

Pope, Alexander 258, 261

Porcel, José Antonio 258

Porras de la Cámara, Francisco 113

Porras, Antonio de 204

Prados, Emilio 348, 352

Prieto, Antonio 338

Properz 126

Proudhon, Pierre-Joseph 304

Proust, Marcel 328

Puértolas, Soledad 342

Pulci 109

Pulgar, Hernando del 33, 44, 68, 69, 216

Pusalgas y Guerris, Ignacio 293

Quevedo y Villegas, Francisco Gómez de $111,112,136,146,147,153-155,211,221$, $222,238,252,253,257$

Quiles, Eduardo 389

Quintana, José Manuel 232, 246, 249, 258, $262,265,288$

Quintilian 48, 215

Quinto, José María de 386

Racine, Jean 310

Radcliffe, Ann 288

Ramos Carrión 301

Raynal, Guillaume-Thomas 247

Recuerda, José Martín 385, 387, 390

Reina y Montilla, Manuel 316

Reina, María Manuela 391

Reinoso, Félix 265

Reverdy, Pierre 347

Rey de Artieda, Andrés 173 
Riaza, Luis 389

Ribadeneira, Pedro de 210

Richard von St. Victor 201

Riera y Coma, José Mariano de 293

Riera, Carmen 342

Rijckel, Dionysius 201

Rimbaud, Arthur 353, 362, 365

Rioja, Francisco de 142, 144

Riquier, Guiraut de 11

Rivadeneyra, Padre 294, 303

Rivas Cherif, Cipriano 373

Ríos, José Amador de los 302

Robbe-Grillet, Alain 335

Rodríguez Buded, Ricardo 387

Rodríguez de la Cámara, Juan (oder del Padrón) 52, 71, 72

Rodríguez de Lena, Pero 70

Rodríguez de Silva Velázquez, Diego 385

Rodríguez Méndez, José María 385, 387

Rodríguez, Alonso 210

Rodríguez, Claudio 361-363

Roi Queimado 11

Rojas Zorrilla, Francisco de 189

Rojas, Carlos 338

Rojas, Fernando de 75, 76

Rolland, Romain 328

Román, Comendador 54

Romero Esteo, Miguel 389

Romero Larrañaga, Gregorio 291

Romero, Concha 391

Ros de Olano 291

Rosales, Luis 354, 355

Rousseau, Jean-Jacques 254, 286

Rueda, Lope de 171-173, 175-177

Rueda, Salvador 316

Ruibal, José 389, 390

Ruiz, Felipe 134

Ruiz, Juan 17, 24, 28

Rusiñol, Santiago 316

Rúha $=$ Rhúa, Pedro de 220

Sa de Miranda, Francisco 122

Saavedra Fajardo, Diego de 224
Saavedra, Angel de (Duque de Rivas) 288, 289, 295, 297, 299, 308

Salas Barbadillo, Alonso Jerónimo de 112

Salinas, Francisco de 133-135

Salinas, Juan de 147

Salinas, Pedro $348,349,377$

Salmerón, Nicolás 303

Salomon 119

Salvo y Vela, Juan 268

Samaniego, Félix María 262

San Pedro, Diego de 33, 54, 71-73, 99

Sanchis Sinisterra, José 391

Sand, George 291, 305

Sannazaro, Jacopo 98, 100, 163

Santa Cruz, Melchor de 218

Santa María, Pablo de 44

Santillana, Marqués de, s. López de Mendoza 32, 33, 38, 39-48, 53, 56-59, 64, 119,123

Sanz del Río, Julián 303

Sanz, Florentino 291

Sarmiento, Martín 241

Sartre, Jean-Paul 335

Sastre, Alfonso $368,369,377,383-386,387$, 390

Sauvetat, Raymond de la 3

Savonarola, Girolamo 201

Sánchez Barbero, Francisco 261, 264

Sánchez de Arévalo, Rodrigo 31, 32

Sánchez de Badajoz, Diego 171

Sánchez de las Brozas, , Francisco (El Brocense) 61, 133

Sánchez de Vercial, Clemente 28, 30

Sánchez Espeso, Germán 340

Sánchez Ferlosio, Rafael 336

Sánchez, Tomás Antonio 242

Scaliger, J. C. 144

Scheeben, Matthias J. 212

Schiller, Friedrich $270,285,287,301$

Schlegel, August Wilhelm 98, 226, 286

Schlegel, Friedrich 132, 286

Schopenhauer, Arthur 315, 325

Scott, Sir Walter 289, 292

Scribe, (Augustin-)Eugène 300 
Sefardi, Rabbi Moises 3

Segovia, Guillén de 48

Selgas y Carrasco, José 306

Sellés, Eugenio 302

Semprún, Jorge 340

Sender, Ramón J. 331, 336, 337

Seneca 30, 32, 44, 106, 173, 215, 223, 317

Serra, Narciso 301

Shakespeare, William 14, 243, 290, 301

Siles, Jaime 365

Silva, Feliciano de 91

Silvela, Francisco 320

Silvestre, Gregorio 121, 145

Sokrates 205

Soto de Rojas 145, 146

Soto de Rojas, Pedro 147

Soto, Luis Barahona de 142, 145, 146

Stein, Edith 212

Stendhal (Henri Beyle) 306, 313

Stigliani, Tommaso 150, 151

Suárez de Figueroa 179, 185

Suárez, Francisco 202, 210

Sue, Eugène 293

Tacitus 223

Tadeo González, Diego 259

Talavera, Hernando de 28, 200

Tamayo y Baus, Manuel 300

Tansillo, Luigi 127

Tapia, Victor 288

Tasso, Bernardo 127

Tasso, Torquato 98

Terenz 59, 165, 166, 178

Teresa von Avila 91, 92, 122, 134, 137, 140, 196, 198, 199, 207, 208, 211

Terrada, Abdón 293

Theokrit 98, 130

Thomas a Kempis 29, 254

Thomas von Aquin 32, 202, 222, 254

Timoneda, Juan de 121, 172, 173

Tob, Sem 30

Tolstoi, Leo $307,311,313,325$

Torbado, Jesús 333

Toreno, Conde de 302
Torquemada, Antonio de 98

Torre, Alfonso de la 33, 70

Torre, Claudio de la 381

Torrente Ballester, Gonzalo 340

Torrepalma, Conde de 259

Torres Naharro, Bartolomé de 165, $167-$ $169,171,176,178$

Torres Villarroel, Diego de 241, 252, 253, 258

Trigo, Felipe 327, 328

Trigueros, Cándido María 251, 255, 261, 273

Trueba y Cosío, Telesforo 292

Trueba y de la Quintana, Antonio de 306

Tusquets, Esther 342

Ulloa, Antonio de 247

Unamuno y Jugo, Miguel de 97, 308, 315$317,319,324,329,343-345,362,368,369$, $372-374,380,384$

Urfé, Honoré d' 100

Valbuena Prat 355

Valdegamas, Marqués de, s. Juan Donoso Cortés 302

Valdés, Alfonso de 203, 218

Valdés, Juan de $90,91,203,204,216,218$, 219

Valdivielso, José de 147, 181

Valente, José Angel $343,355,360,361,362$, 363, 366

Valera y Alcalá-Galiano, Juan 283, 308, 309, 311, 316

Valéry, Paul 349

Valla, Lorenzo 133

Valladares de Sotomayor, Antonio 246, 255

Valladolid, Alfonso de 28

Valle-Inclán, Ramón María del 315, 316, 324, 326, 327, 368-370, 372, 374-377, 379, $380,382,384,385,387-390$

Vallejo, Alfonso 391

Vallés, Pedro 112

Vargas Llosa, Mario 335, 339

Vázquez Montalbán, Manuel 341 
Vega Carpio, Lope Félix de 101, 104, 120 , $136,145-149,155,161,168,174,175,177-$ $179,181-184,187,242,243,267,270,292$, 294, 309

Vega, Pedro de la 90

Vega, Ricardo de la 301

Vega, Ventura de la 300

Velázquez de Velasco, Luis José 242

Venegas, Alejo 90, 204, 216

Vergil 32, 51, 60, 98, 104, 105, 126, 127, 130132,163

Vélez de Guevara, Luis 181

Vicente, Gil 121, 122, 168-171

Villaespesa, Francisco 316, 376

Villalón, Cristóbal de 216, 218

Villamediana, , Conde de (Juan de Tassis) 147

Villegas, Estéban Manuel de 257, 259

Villena, Enrique de $32,40,41,53,70$

Vincent de Beauvais 18

Virués, Cristóbal de 173

Vitoria, Francisco de 234
Vivanco, Luis Felipe 354,355

Vivas, Joâo 21

Vives, Juan Luis 90, 204, 205, 216, 219, 220

Voltaire 276

Washington, Irving 286

Xavier, Franz 140

Xirgu, Margarita 373

Yáñez, Rodrigo 23

Young, Edward 258, 264

Zabala y Zamora, Gaspar 255

Zamacois, Eduardo 327,328

Zamora, Antonio de 268

Zapata, Luis 218

Zerbolt van Zutphen, Gerhard 201

Zola, Émile 309, 310

Zorrilla y Moral, José $268,290,294,295$, 299, 307, 376 